\title{
Building earthquake resilience in sustainable cities in terms of input energy
}

\author{
AUTHOR(S):
}

Kojima, K.; Fujita, K.; Takewaki, I.

\section{CITATION:}

Kojima, K....[et al]. Building earthquake resilience in sustainable cities in terms of input energy. Sustainable Cities and Society 2014, 12: 46-62

\section{ISSUE DATE:}

2014-07

URL:

http://hdl.handle.net/2433/187357

\section{RIGHT:}

C 2014 Elsevier B.V.; この論文は出版社版でありません。引用の際には 出版社版をご確認ご利用ください。; This is not the published version. Please cite only the published version. 


\title{
Review: Building earthquake resilience in sustainable cities in terms of input energy
}

\author{
K. Kojima, K. Fujita and I. Takewaki* \\ Department of Architecture and Architectural Engineering \\ Graduate School of Engineering, Kyoto University \\ Kyotodaigaku-Katsura, Nishikyo-ku, Kyoto 615-8540, Japan
}

\begin{abstract}
Input energy to building structures during earthquakes is an important index to measure the influence of earthquake ground motions on building structures. Such input energy can be defined after the structural system is specified and the input mechanism is described clearly. The energy input to structures consists mainly of the energy dissipated by hysteretic deformation and that by viscous damping. The excessive dependence on the former mechanism leads to unrepairable and unpreferable states of structures after earthquakes which should be avoided from the viewpoint of sustainability of building structures and cities. In this sense, the measure of energy is appropriate from the viewpoint of total management of buildings in a sustainable city. Then the upper bound of earthquake input energy is derived and discussed under uncertain conditions on input ground motions. It is shown that the earthquake energy input rate is another key parameter for measuring the instantaneous effect of earthquake ground motions on structural responses. A historical review is also made on the development of treatment of earthquake input energy into buildings and on its role into greater building earthquake resilience in sustainable cities.
\end{abstract}

Keywords: Sustainable buildings, Earthquake engineering, Earthquake input energy

*Corresponding author, E-mail: takewaki@archi.kyoto-u.ac.jp 


\section{Introduction}

When an earthquake occurs beneath or near a city, all the buildings in the city are shaken more or less. In the conventional seismic structural engineering, the deformation and force are treated as major key indices and their relations with the deformation limit and strength play key roles. However the factor of the size of buildings is not reflected in these indices. The energy dissipated in a building during an earthquake is an alternate measure and can reflect the size of the building because all the energies dissipated in parts of the building are summed up over the building. It is discussed in this review article that the measure of energy is appropriate from the viewpoint of total management of buildings in a sustainable city.

It has been recognized for many years that, if the total mass of a building is given, the earthquake input energy is constant irrespective of the stiffness and strength of the building, i.e. the damage level of the building (Housner 1956, 1959 Akiyama 1985). The earthquake input energy is transformed principally into (1) the energy dissipated by hysteretic deformation and viscous (or frictional) damping system and (2) the kinetic energy which will diminish during a damping process. It is usually believed that the energy consumption by hysteretic deformation is related to the structural damage. On the other hand, the energy consumption by viscous (or frictional) damping is not related to the structural damage directly. In the earthquake structural engineering community, it is accepted that a certain limited damage is allowed from the viewpoint of the building cost. The key issue is how the damage level is controlled in comparison with the shaking level of ground motions. The introduction of smart passive control technologies (Takewaki et al. 2011, Murase et al. 2013) may be one approach to provide a reasonable and acceptable solution to such difficult problems.

First of all, it is shown that the constancy of earthquake input energy is directly related to the uniformity of 'the Fourier amplitude spectrum' of ground motion acceleration with respect to frequency, not the uniformity of the velocity response spectrum with respect to natural period. Since the earthquake ground motions are highly uncertain in both aleatory and epistemic senses, the description of such uncertainties is important for reliable design of structures under the earthquake ground motions. The worst-case analysis is promising (Takewaki 2013a, b, Takewaki et al. 2012) and the bounds of earthquake input energy play an important role. The bounds under acceleration and velocity constraints (time integral of the squared base acceleration and time integral of the squared base velocity) are clarified through numerical examinations for recorded ground motions to be meaningful in the short and intermediate/long natural period ranges, respectively.

\section{Earthquake input energy to fixed-base SDOF models}

A lot of works have been accumulated on earthquake input energy. The representative ones are Tanabashi 1956; Housner 1956, 1959; Berg and Thomaides 1960; Goel and Berg 1968; Housner and Jennings 1975; Mahin and Lin 1983; Zahrah and Hall 1984; Akiyama 1985; Uang and Bertero 1990; Leger and Dussault 1992; Kuwamura et al. 1994; Fajfar and Vidic 1994; Riddell and Garcia 2001; Ordaz et al. 2003. Different from most of the conventional works, the earthquake input energy was formulated in the frequency domain (Page 1952; Lyon 1975, Ordaz et al. 2003, Takewaki 2004a, b, 2005a-d, 2006a-c, 2007a, b, 2013a, b, Takewaki and Fujimoto 2004, Takewaki and Fujita 2009, Takewaki et al. 2011, 2013, Kishida and Takewaki 2006, 2007) to facilitate the formulation of critical excitation methods and the derivation of bounds of the earthquake input energy.

Consider a damped, linear elastic SDOF system of mass $m$, stiffness $k$ and damping coefficient $c$ as shown in Fig.1. Let $\Omega=\sqrt{\mathrm{k} / \mathrm{m}}, h=c /(2 \Omega \mathrm{m})$ and $x$ denote the undamped natural circular frequency, the damping ratio and the displacement of the mass relative to the 
ground. An over-dot indicates the time derivative. The input energy to the SDOF system by a horizontal ground acceleration $\ddot{u}_{g}(t)=a(t)$ from $t=0$ to $t=t_{0}$ (end of input) can be defined by the work of the ground on the SDOF structural system and is expressed by

$$
E_{I}=\int_{0}^{t_{0}} m\left(\ddot{u}_{g}+\ddot{x}\right) \dot{u}_{g} \mathrm{~d} t
$$

The term $-m\left(\ddot{u}_{g}+\ddot{x}\right)$ in Eq.(1) indicates the inertial force and is equal to the sum of the restoring force $k x$ and the damping force $c \dot{x}$ in the model. Fig.1 shows a schematic diagram for evaluating the input energy to this SDOF model. It can be observed that the restoring force equilibrating with the inertial force has an opposite direction to the base motion increment.

Integration by parts of Eq.(1) yields

$$
\begin{aligned}
E_{I} & =\int_{0}^{t_{0}} m\left(\ddot{x}+\ddot{u}_{g}\right) \dot{u}_{g} \mathrm{~d} t=\int_{0}^{t_{0}} m \ddot{x} \dot{u}_{g} \mathrm{~d} t+\left[(1 / 2) m \dot{u}_{g}{ }^{2}\right]_{0}^{t_{0}} \\
& =\left[m \dot{x} \dot{u}_{g}\right]_{0}^{t_{0}}-\int_{0}^{t_{0}} m \dot{x} \ddot{u}_{g} \mathrm{~d} t+\left[(1 / 2) m \dot{u}_{g}{ }^{2}\right]_{0}^{t_{0}}
\end{aligned}
$$

Assume that $\dot{x}=0$ at $t=0$ and $\dot{u}_{g}=0$ at $t=0$ and $t=t_{0}$. Then the total input energy can be simplified to the following form.

$$
E_{I}=-\int_{0}^{t_{0}} m \ddot{u}_{g} \dot{x} \mathrm{~d} t
$$

It is known (Page 1952; Lyon 1975; Ordaz et al. 2003, Takewaki 2004a, b) that the total input energy per unit mass to the SDOF system can also be expressed in the frequency domain by use of Fourier transformation.

$$
\begin{aligned}
E_{I} / m & =-\int_{-\infty}^{\infty} \dot{x} a \mathrm{~d} t=-\int_{-\infty}^{\infty}\left[(1 / 2 \pi) \int_{-\infty}^{\infty} \dot{X} e^{\mathrm{i} \omega t} \mathrm{~d} \omega\right] a \mathrm{~d} t \\
& =-(1 / 2 \pi) \int_{-\infty}^{\infty} A(-\omega)\left\{H_{V}(\omega ; \Omega, h) A(\omega)\right\} \mathrm{d} \omega \\
& \equiv \int_{0}^{\infty}|A(\omega)|^{2} F(\omega) \mathrm{d} \omega
\end{aligned}
$$

In Eq.(4), the function $H_{V}(\omega, \Omega, h)$ is the velocity transfer function defined by $\dot{X}(\omega)=$ $H_{V}(\omega ; \Omega, h) A(\omega)$ and $F(\omega)=-\operatorname{Re}\left[H_{V}(\omega ; \Omega, h)\right] / \pi$. The function $F(\omega)$ is called the energy transfer function and plays a key role in evaluating the upper bound of input energy which will be discussed in the following section. $\dot{X}(\omega)$ and $A(\omega)$ denote the Fourier transforms of $\dot{x}$ and $\ddot{u}_{g}(t)=a(t)$. The symbol i indicates the imaginary unit. The velocity transfer function $H_{V}(\omega ; \Omega, h)$ can be expressed by

$$
H_{V}(\omega ; \Omega, h)=-\mathrm{i} \omega /\left(\Omega^{2}-\omega^{2}+2 \mathrm{i} h \Omega \omega\right)
$$

Eq.(4) implies that the earthquake input energy to damped, linear elastic SDOF systems does not depend on the phase of input motions. This is well known (Page 1952, Lyon 1975, 
Kuwamura et al. 1994, Ordaz et al. 2003, Takewaki 2004a, b). It can also be observed from Eq.(4) that the function $F(\omega)$ plays a central role in the evaluation of the earthquake input energy and may have some influence on the investigation of constancy of the earthquake input energy to structures with various model parameters. The property of the function $F(\omega)$ in Eq.(4) will therefore be clarified in the following section in detail.

Fig. 2 shows an example of the time history of input energy and various component energies in an elastic-plastic structure (two-story model). It can be observed that, while the hysteretic energy attains its maximum at about time $=10$ (s) (when the plastic deformation process ends), the damping energy increases gradually even after time $=10(\mathrm{~s})$. There exist many research works on earthquake input energy to elastic-plastic structures, e.g. Housner 1956, 1959, Akiyama 1985, Berg and Thomaides 1960; Goel and Berg 1968, Mahin and Lin 1983; Zahrah and Hall 1984; Akiyama 1985; Uang and Bertero 1990; Leger and Dussault 1992; Kuwamura et al. 1994; Fajfar and Vidic 1994; Hall et al. 1995; Iyama and Kuwamura 1999; Riddell and Garcia 2001, Bozorgnia and Bertero 2003, Khashaee 2004, Choi and Kim 2006, Kalkan and Kunnath 2008. Recently the hysteretic energy dissipation is used effectively in passively controlled structures (Soong and Dargush 1997, Christopoulos and Filiatrault 2006, Takewaki 2009). In order to make the earthquake resistant design more reliable, some challenges are also being conducted for identifying the critical earthquake input for maximizing the hysteretic energy or damage (Moustafa and Takewaki 2009, 2010, Moustafa et al. 2010, Moustafa 2011, Takewaki et al. 2012, Zhai et al. 2013).

Fig.3 illustrates the total input energy of Kobe University NS, Hyogo-ken Nanbu 1995 with respect to natural period of structures. In Fig.3, the upper bound of the input energy for specified acceleration power (Section 5) and the upper bound of the input energy for specified velocity power (Section 6) are also shown (see Fig.4).

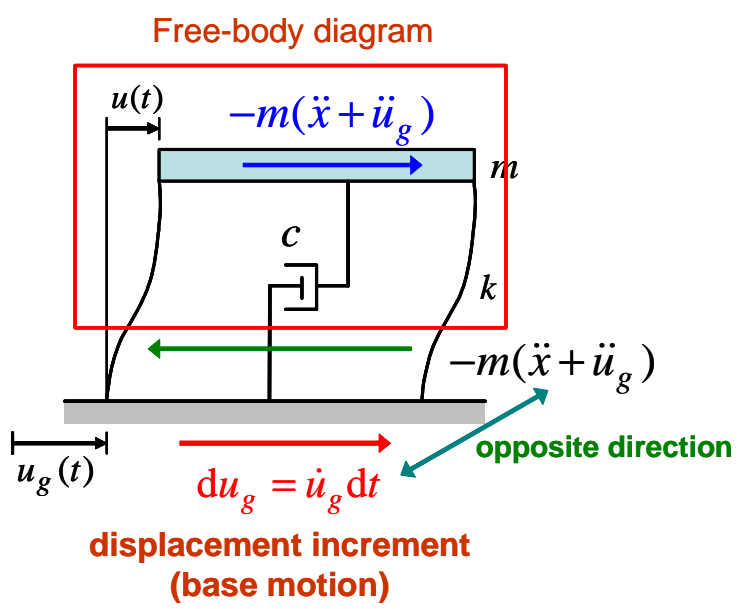

Fig.1 Schematic diagram for evaluating input energy to SDOF model 


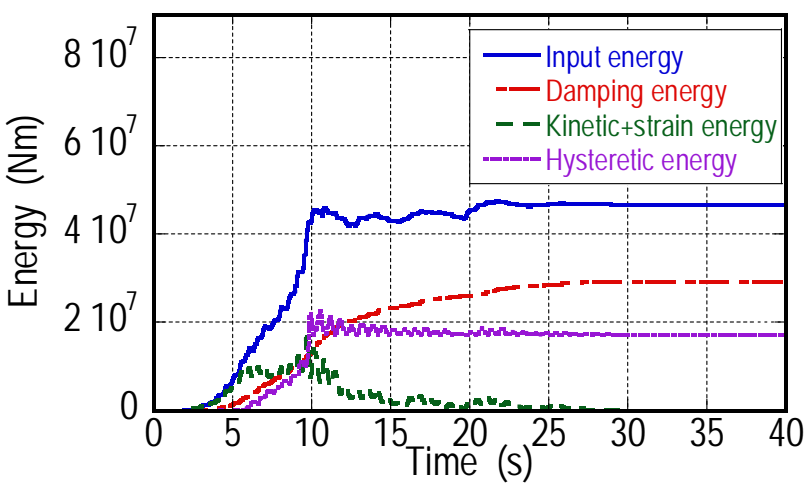

Fig.2 Time history of input energy and various component energies

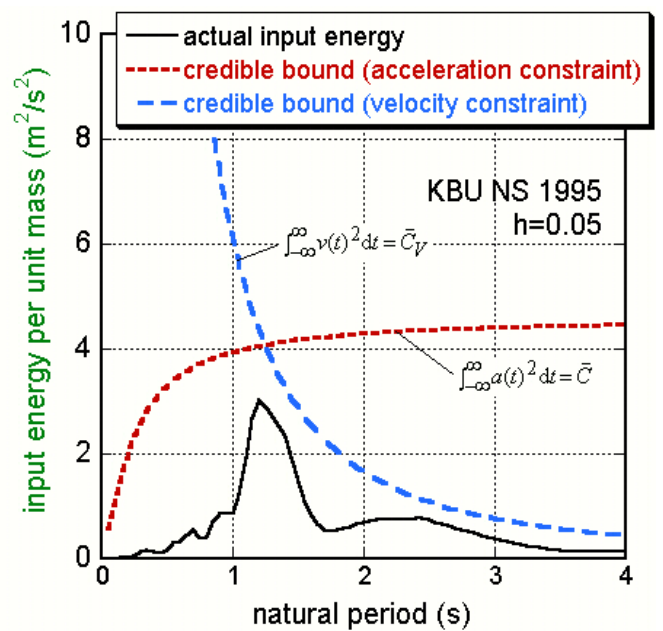

Fig.3 Total input energy of Kobe University NS, Hyogo-ken Nanbu 1995 with respect to natural period of structures and its upper bounds

$$
\begin{aligned}
& \int_{-\infty}^{\infty} a(t)^{2} \mathrm{~d} t=(1 / \pi) \int_{0}^{\infty}|A(\omega)|^{2} \mathrm{~d} \omega=\bar{C}_{A} \\
& \int_{-\infty}^{\infty} v(t)^{2} \mathrm{~d} t=(1 / \pi) \int_{0}^{\infty}|V(\omega)|^{2} \mathrm{~d} \omega=\bar{C}_{V}
\end{aligned}
$$

setting of maximum velocity

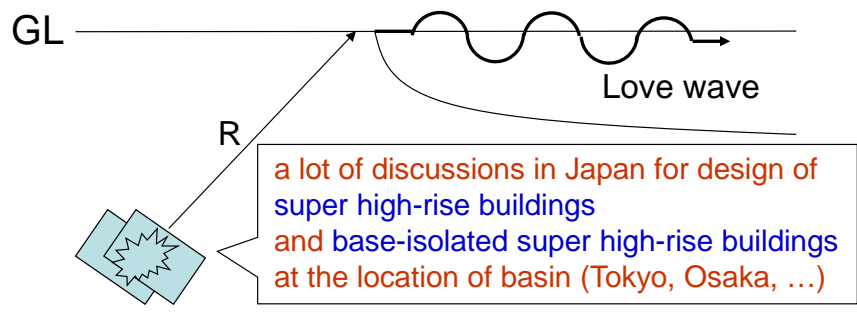

Fig.4 Acceleration power and velocity power for defining earthquake power 


\section{Role of energy transfer function and constancy of earthquake input energy}

The functions $F(\omega)$ in Eq.(4) for various model natural periods $T=0.5,1.0,2.0$ s and damping ratios $h=0.05,0.20$ are plotted in Fig.5. The area of $F(\omega)$ can be proved to be constant irrespective of $\Omega$ and $h$. This property for any damping ratio has already been pointed out by Ordaz et al. (2003). However, its proof has not been presented there and the proof has been provided by Takewaki (Takewaki 2004b).

The energy transfer function $F(\omega)$ introduced in Eq.(4) can also be expressed by

$$
F(\omega)=\frac{2 h \Omega \omega^{2}}{\pi\left\{\left(\Omega^{2}-\omega^{2}\right)^{2}+(2 h \Omega \omega)^{2}\right\}}
$$

$F(\omega)$ is a positive function. The following relation holds (Takewaki 2004b).

$$
2 \int_{0}^{\infty} F(\omega) \mathrm{d} \omega=1
$$

Eq.(7) implies that the area of $F(\omega)$ is constant irrespective of $\Omega$ and $h$.

From Eqs.(4) and (7), if the Fourier amplitude spectrum of an input ground acceleration is uniform with respect to frequency, the earthquake input energy to a damped, linear elastic SDOF system per unit mass is exactly constant irrespective of $\Omega$ and $h$. Let $S_{V}(h=0)$ denote the velocity response spectrum of the input for null damping ratio. If $|A(\omega)|$ is exactly constant with respect to frequency and an assumption $|A(\Omega)| \cong S_{V}(h=0)$ holds (Hudson 1962), Eqs.(4) and (7) provide

$$
E_{I} \cong \frac{1}{2} m\left\{S_{V}(h=0)\right\}^{2}
$$

Eq.(8) may be similar to the maximum total energy proposed by Housner (1956, 1959). Housner (1959) discussed the maximum total energy defined by $E_{H}=\max _{t}\left\{-\int_{0}^{t} m \ddot{u}_{g} \dot{x} \mathrm{~d} t\right\}$ instead of $E_{I}$ defined by Eq.(3) and introduced some assumptions, e.g. slowly-varying property of the total energy. A general inequality $S_{V}(h \neq 0) \leq S_{V}(h=0)$ for any damping ratio and a more exact relation $|A(\Omega)| \leq S_{V}(h=0)$ can also be demonstrated for most cases. If $S_{V}(h \neq 0) \cong|A(\Omega)|=$ constant holds for a specific damping ratio denoted by $h_{a}$, Eq.(8) may be replaced by $E_{I} \cong(1 / 2) m\left\{S_{V}\left(h_{a}\right)\right\}^{2}$. While Housner discussed the constancy of earthquake input energy (maximum total energy) with respect to natural period by focusing on the uniformity of a velocity response spectrum with respect to natural period (Housner 1956, 1959), another view point has been introduced in this section. The constancy of input energy defined by Eq.(3) is directly related to the constancy of 'the Fourier amplitude spectrum' of a ground motion acceleration, not the constancy of the velocity response spectrum. 


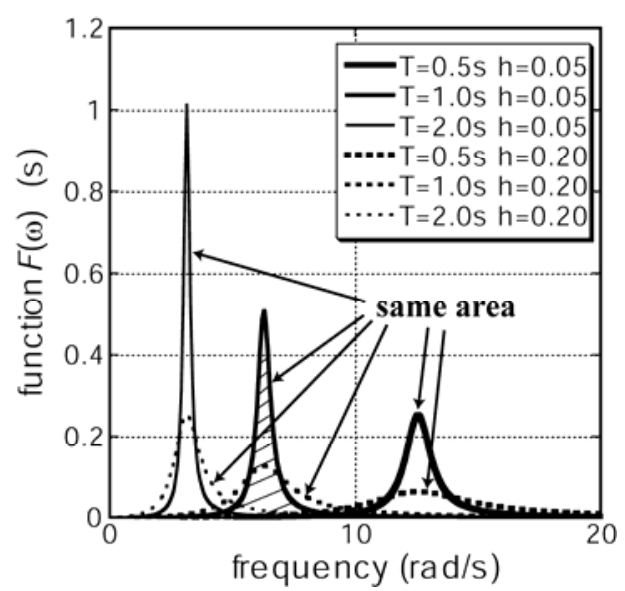

Fig.5 Function $F(\omega)$ for natural periods $T=0.5,1.0$, 2.0s and damping ratios $h=0.05,0.20$

(Takewaki 2004b)

\section{Earthquake input energy to fixed-base MDOF models}

Consider a proportionally damped, linear elastic multi-degree-of-freedom (MDOF) shear building model of mass matrix $[M]$ subjected to a horizontal ground acceleration $\ddot{u}_{g}(t)=a(t)$. The parameters $\Omega_{i}, h_{i}$ and $\{x\}$ denote the $i$-th undamped natural circular frequency, the $i$-th damping ratio and a set of the horizontal floor displacements relative to the ground, respectively. The input energy to such system by the ground motion from $t=0$ to $t=t_{0}$ (end of input) can be defined by the work of the ground on that system (Uang and Bertero 1990) and is expressed by

$$
E_{I}=\int_{0}^{t_{0}}\{1\}^{T}[M]\left(\{1\} \ddot{u}_{g}+\{\ddot{x}\}\right) \dot{u}_{g} \mathrm{~d} t
$$

where $\{1\}=\{1 \cdots 1\}^{T}$. The term $\{1\}^{T}[M]\left(\{1\} \ddot{u}_{g}+\{\ddot{x}\}\right)$ in the integrand indicates the sum of the horizontal inertial forces acting on the system with minus sign. Double minus signs result in the positive sign. Integration by parts of Eq.(9) yields

$$
E_{I}=\left[(1 / 2)\{1\}^{T}[M]\{1\} \dot{u}_{g}{ }^{2}\right]_{0}^{t_{0}}+\left[\{\dot{x}\}^{T}[M]\{1\} \dot{u}_{g}\right]_{0}^{t_{0}}-\int_{0}^{t_{0}}\{\dot{x}\}^{T}[M]\{1\} \ddot{u}_{g} \mathrm{~d} t
$$

As in an SDOF model, assume that $\{\dot{x}\}=\{0\}$ at $t=0$ and $\dot{u}_{g}=0$ at $t=0$ and $t=t_{0}$. Then the total input energy $E_{I}$ can be reduced finally to the following form:

$$
E_{I}=-\int_{0}^{t_{0}}\{\dot{x}\}^{T}[M]\{1\} \ddot{u}_{g} \mathrm{~d} t
$$

As in the case for an SDOF model, the input energy can also be expressed in the frequency domain. Let $\{\dot{X}\}$ denote the Fourier transform of $\{\dot{x}\}$. Application of the Fourier inverse transformation of the relative nodal velocities $\{\dot{x}\}$ into Eq.(11) provides 


$$
E_{I}=-\frac{1}{2 \pi} \int_{-\infty}^{\infty}\{\dot{X}\}^{T}[M]\{1\} A(-\omega) \mathrm{d} \omega
$$

Introduce the following coordinate transformation

$$
\{x\}=[\Phi]\{q\}
$$

$[\Phi]$ is the modal matrix consisting of modal vectors and $\{q\}$ is defined by

$$
\begin{aligned}
& \{q\}=\left\{\cdots q_{i} \cdots\right\}^{T}, \\
& q_{i}=\int_{0}^{t}\left\{-\ddot{u}_{g}(\tau)\right\} g_{i}(t-\tau) \mathrm{d} \tau
\end{aligned}
$$

In Eqs.(14a, b), the parameters $q_{i}$ and $g_{i}(t)=\left(1 / \Omega_{D i}\right) \exp \left(-h_{i} \Omega_{i} t\right) \sin \Omega_{D i} t$ denote the normal coordinate and the unit impulse response function for under-damped vibration, respectively, and $\Omega_{D i}=\Omega_{i} \sqrt{1-h_{i}^{2}}$ is the $i$-th damped natural circular frequency, respectively. In the case where over-damped vibration modes appear, the corresponding unit impulse response function has to be modified. This case will be explained later for non-proportionally damped models. The input energy can be derived by substituting the coordinate transformation $\{\dot{x}\}=[\Phi]\{\dot{q}\}$, its Fourier transform $\{\dot{X}\}=[\Phi]\{\dot{Q}\}$ and the velocity transfer relation $\{\dot{Q}\}=\left\{H_{V}\right\} A$ into Eq.(12).

$$
E_{I}=\int_{0}^{\infty} F_{M P}(\omega)|A(\omega)|^{2} \mathrm{~d} \omega
$$

$\left\{H_{V}\right\}$ and $F_{M P}(\omega)$ in Eq.(15) are the velocity transfer function vector with respect to base acceleration and the energy transfer function for an MDOF model, respectively, and are expressed by

$$
\begin{aligned}
& \left\{H_{V}\right\}=\left\{\cdots H_{V i} \cdots\right\}^{T}, \\
& H_{V i}\left(\omega ; \Omega_{i}, h_{i}\right)=-\mathrm{i} \omega /\left(\Omega_{i}^{2}-\omega^{2}+2 \mathrm{i} h_{i} \Omega_{i} \omega\right), \\
& F_{M P}(\omega)=-\frac{1}{\pi} \operatorname{Re}\left[\left\{H_{V}\right\}^{T}[\Phi]^{T}[M]\{1\}\right]
\end{aligned}
$$

The symbol $\mathrm{Re}[\cdot]$ indicates the real part of a complex number.

In order to examine the accuracy of the modal superposition method in the frequency domain, another method is used without modal decomposition. This method is applicable to both proportionally damped and non-proportionally damped structures. Using the Fourier transformation of the equations of motion, the Fourier transform $\{\dot{X}(\omega)\}$ of the nodal velocities can be expressed by

$$
\{\dot{X}(\omega)\}=-\mathrm{i} \omega\left(-\omega^{2}[M]+\mathrm{i} \omega[C]+[K]\right)^{-1}[M]\{1\} A(\omega)
$$


The input energy can then be computed by Eq.(12). The input energy without modal decomposition may be evaluated by

$$
E_{I}=\int_{0}^{\infty} F_{M}(\omega)|A(\omega)|^{2} \mathrm{~d} \omega
$$

$F_{M}(\omega)$ and $[Y(\omega)]$ are defined by

$$
\begin{aligned}
& F_{M}(\omega)=\operatorname{Re}\left[\mathrm{i} \omega\{1\}^{T}[M]^{T}[Y(\omega)][M]\{1\}\right] / \pi \\
& {[Y(\omega)]=\left(-\omega^{2}[M]+\mathrm{i} \omega[C]+[K]\right)^{-1}}
\end{aligned}
$$

The computation of $[Y(\omega)]=\left(-\omega^{2}[M]+\mathrm{i} \omega[C]+[K]\right)^{-1}$ for many frequencies is quite time-consuming especially for structures with many degrees of freedom. Careful attention is therefore necessary in the method without modal decomposition.

\section{Bound of earthquake input energy using acceleration constraint}

In the last century, the power or degree of destructiveness of ground motions was frequently discussed in the building seismic resistant design (for example, Housner 1975, Housner and Jennings 1975). The time integral (acceleration power) of the squared ground acceleration and the time integral (velocity power) of the squared ground velocity were thought to be two representative measures of power for damage potential.

It is explained in this section that a critical excitation method (Drenick 1970) for the earthquake input energy can provide upper bounds on the input energy. Westermo (1985) has tackled a similar problem for the maximum input energy to an SDOF system subjected to external forces. However the solution is restrictive because it includes the velocity response containing the solution itself implicitly. A more general solution procedure will be explained here.

The capacity of ground motions is often discussed in terms of the time integral of $a(t)^{2}$ (Arias 1970; Housner and Jennings 1975; Riddell and Garcia 2001). This quantity is well known as the Arias intensity measure while the coefficient is different. The constraint on this quantity can be expressed by

$$
\int_{-\infty}^{\infty} a(t)^{2} \mathrm{~d} t=(1 / \pi) \int_{0}^{\infty}|A(\omega)|^{2} \mathrm{~d} \omega=\bar{C}_{A}
$$

$\bar{C}_{A}$ is the specified value of the time integral of $a(t)^{2}$. Another index called a 'power' (average rate of energy supplied) has been defined by dividing that quantity by its significant duration (Housner 1975). It is also clear that the maximum value of the Fourier amplitude spectrum of the input is finite. The infinite Fourier amplitude spectrum may represent a perfect harmonic function or that multiplied by an exponential function (Drenick 1970). This is unrealistic as an actual ground motion while a similar phenomenon has been observed recently (long-period ground motion; Takewaki et al. 2012). The constraint on this property may be expressed by

$$
|A(\omega)| \leq \bar{A} \quad(\bar{A} \text { : specified value })
$$

The critical excitation problem for the acceleration power may then be stated as follows: 


\section{[Critical excitation problem for acceleration]}

Find the Fourier amplitude $|A(\omega)|$ of acceleration input that maximizes the earthquake input energy per unit mass expressed by Eq.(4) subject to the constraints (21) and (22) on acceleration.

It is known in the references (Takewaki 2001a, b, 2002a, b) on power spectral density functions that, if $\bar{A}$ is infinite, the critical function of $|A(\omega)|^{2}$ turns out to be the Dirac delta function which has a non-zero value only at the point maximizing $F(\omega)$. On the other hand, if $\bar{A}$ is finite, the critical one of $|A(\omega)|^{2}$ yields a rectangular function attaining $\bar{A}^{2}$. The band-width of the frequency can be obtained as $\Delta \omega=\pi \bar{C}_{A} / \bar{A}^{2}$. The location of the rectangular function, i.e. the lower and upper limits, can be computed by maximizing $\bar{A}^{2} \int_{\omega_{L}}^{\omega_{U}} F(\omega) \mathrm{d} \omega$. It should be reminded that $\omega_{U}-\omega_{L}=\Delta \omega$. It can be shown without difficulty that a good and simple approximation is given by $\left(\omega_{U}+\omega_{L}\right) / 2=\Omega$. The essential feature of the solution procedure explained in this section is shown in Fig.6. The Westermo's periodic solution (Westermo 1985) can be interpreted to correspond to the case of infinite value of $\bar{A}$.

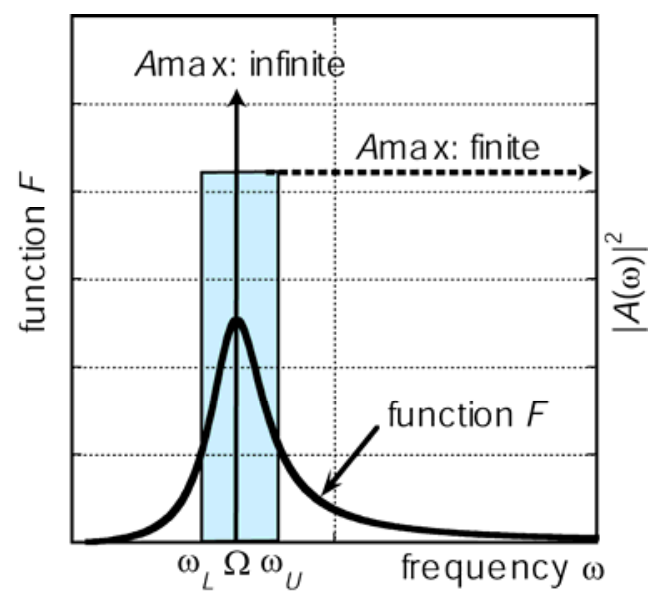

Fig.6 Schematic diagram of solution procedure for critical excitation problem with acceleration constraints

The absolute bound may be computed for the infinite value of $\bar{A}$. This absolute bound can be evaluated as $\bar{C}_{A} /(2 h \Omega)$ by introducing an assumption that $F(\omega)$ attains its maximum at $\omega=\Omega$ and substituting Eq.(21) into Eq.(4).

\section{Bound of earthquake input energy using velocity constraint}

It has often been discussed that the maximum ground acceleration controls the behavior of structures with short natural periods and the maximum ground velocity does the behavior of structures with intermediate or rather long natural periods (see, for example, Tanabashi 1956, Takewaki 2006c). Consider the following constraint on the ground motion velocity $\dot{u}_{g}(t)=v(t)$ (Housner 1975, Housner and Jennings 1975, Takewaki and Tsujimoto 2011). 


$$
\int_{-\infty}^{\infty} v(t)^{2} \mathrm{~d} t=(1 / \pi) \int_{0}^{\infty}|V(\omega)|^{2} \mathrm{~d} \omega=\bar{C}_{V} \quad\left(\bar{C}_{V}: \text { specified value }\right)
$$

$V(\omega)$ is the Fourier transform of the ground velocity $v(t)$. With the relation $A(\omega)=\mathrm{i} \omega V(\omega)$ kept in mind, Eq.(4) can be reduced to

$$
E_{I} / m=\int_{0}^{\infty}|V(\omega)|^{2} \omega^{2} F(\omega) \mathrm{d} \omega
$$

The maximum value of $|V(\omega)|$ is certainly finite in a realistic situation. The constraint on the upper limit on $V(\omega)$ may be expressed by

$$
|V(\omega)| \leq \bar{V} \quad(\bar{V}: \text { upper limit of } V(\omega))
$$

The critical excitation problem for the velocity constraints may be described as follows:

\section{[Critical excitation problem for velocity]}

Find the Fourier amplitude $|V(\omega)|$ of the velocity input that maximizes the earthquake input energy per unit mass expressed by Eq.(24) subject to the constraints (23) and (25) on velocity.

It is apparent that almost the same procedure for solving the critical excitation problem as for acceleration constraints can be used by replacing $A(\omega)$ and $F(\omega)$ by $V(\omega)$ and $\omega^{2} F(\omega)$, respectively. The functions $\omega^{2} F(\omega)$ for three model natural periods $T=0.5,1.0$, 2.0s and two model damping ratios $h=0.05,0.20$ are plotted in Fig.7. It can be seen that $\omega^{2} F(\omega)$ becomes larger in the peak and wider in the frequency range with increase of the model natural frequency. In case of a finite value of $\bar{V}$, the band-width of the critical rectangular function $|V(\omega)|^{2}$ can be derived from $\Delta \omega=\pi \bar{C}_{V} / \bar{V}^{2}$. The upper and lower frequency limits of the rectangular function can be specified by maximizing the value $\bar{V}^{2} \int_{\omega_{L}}^{\omega_{U}} \omega^{2} F(\omega) \mathrm{d} \omega$ where $\omega_{U}-\omega_{L}=\Delta \omega$. A good and simple approximation can be obtained without difficulty by $\left(\omega_{U}+\omega_{L}\right) / 2=\Omega$. The essential feature of the solution procedure is shown in Fig.8.

The absolute bound may be computed for the infinite value of $\bar{V}$. This absolute bound can be evaluated as $\Omega \bar{C}_{V} /(2 h)$ by using an assumption that $\omega^{2} F(\omega)$ attains its maximum at $\omega=\Omega$ and substituting Eq.(23) into Eq.(24). 


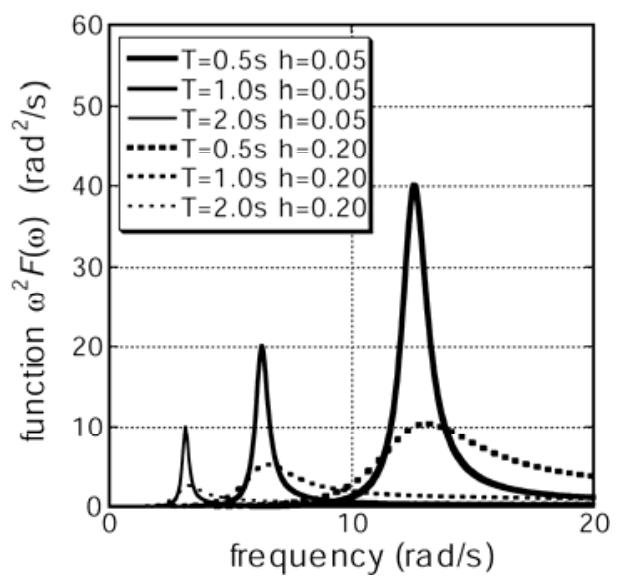

Fig.7 Function $\omega^{2} F(\omega)$ for model natural periods $T=0.5$, 1.0, 2.0s and model damping ratios $h=0.05,0.20$ (Takewaki 2004b)

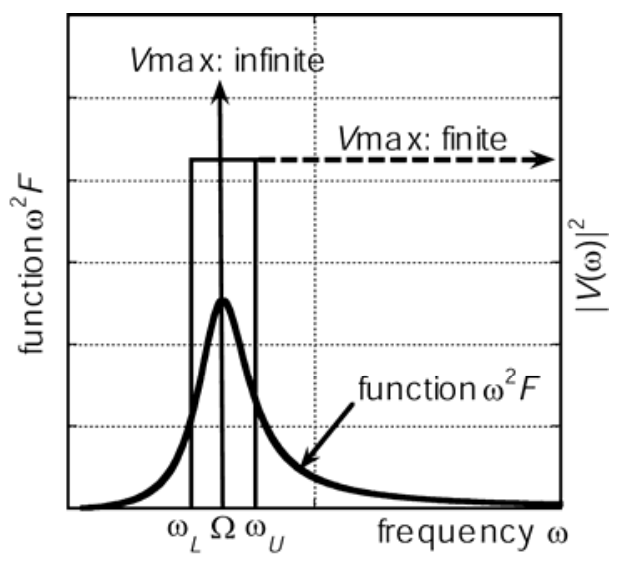

Fig.8 Schematic diagram of solution procedure for critical excitation problem with velocity constraints (Takewaki 2004b)

\section{Earthquake input energy to soil-structure interaction models}

Most of past devastating earthquakes have demonstrated that, while intensive ground motions are recorded around building structures, the damages to those structures are not always serious. The selection of appropriate intensity measures (peak acceleration, peak velocity, input energy, Housner spectral intensity, Arias intensity (Arias 1970) etc.) of ground motions and soil-structure interaction (SSI) effects may be key factors to these arguments.

A new method for evaluating the earthquake input energy to SSI systems is discussed here. The method is an approach in the frequency domain (Takewaki 2005b). Because the inertial interaction (foundation impedance) and the kinematic interaction (effective input motion) are well described by frequency-dependent functions, the approach based on the frequency domain analysis is appropriate and effective.

Fig.9 shows the mechanism of earthquake energy input to a soil-structure system. The left figure shows the input energy to the overall system including the soil springs and dashpots. The reaction on the overall system (horizontal component only in this case) is considered. On the other hand, the right figure presents the input energy to the superstructure. The reactions on the superstructure (horizontal and rotational components in this case) are taken into account. 


\section{Free-body diagram}

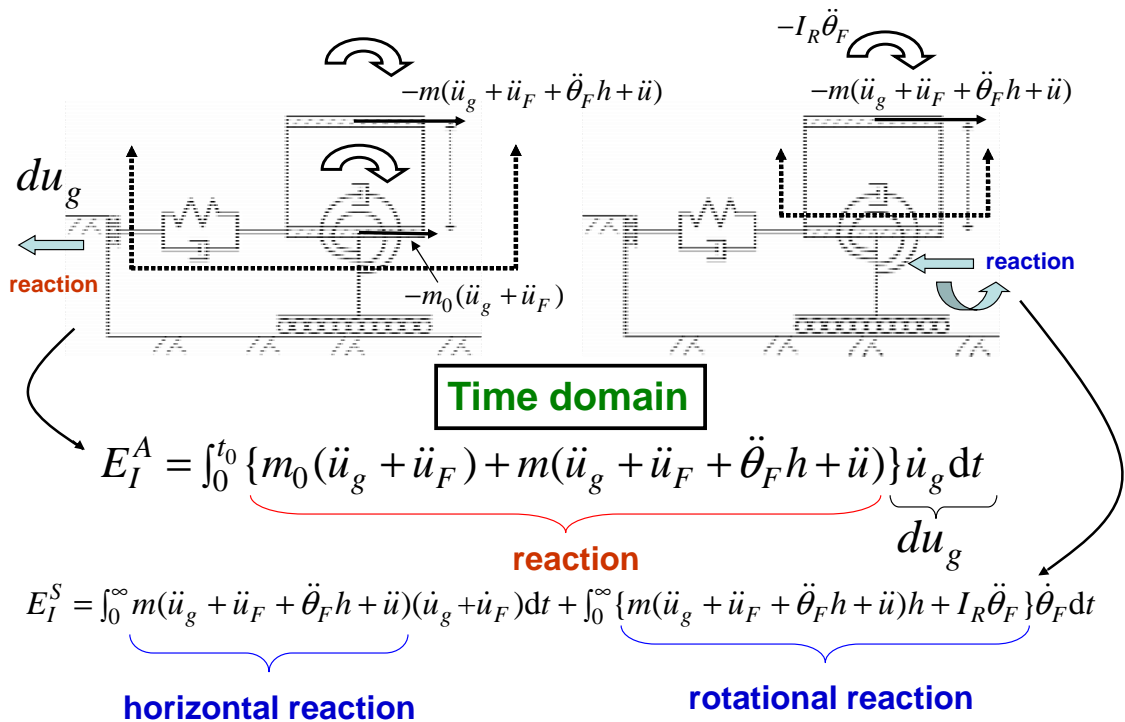

Fig.9 Mechanism of earthquake energy input to soil-structure system

Fig.10 shows earthquake input energy time histories to an overall system and a structure only. On the other hand, Fig.11 illustrates the credible and absolute bounds of earthquake input energies to an overall system and a structure only with respect to the natural period of the structure. It can be observed from Fig.11 that, while no special property is seen in El Centro NS and JMA Kobe NS, a clear amplification can be seen in SCT1 of Mexico earthquake (about 2s) and Kobe University (KBU) NS (about 1.2s). It can be understood that this amplification is caused by resonance and the approaching to the upper bound implies the existence of the nearly worst input in actual recorded ground motions.

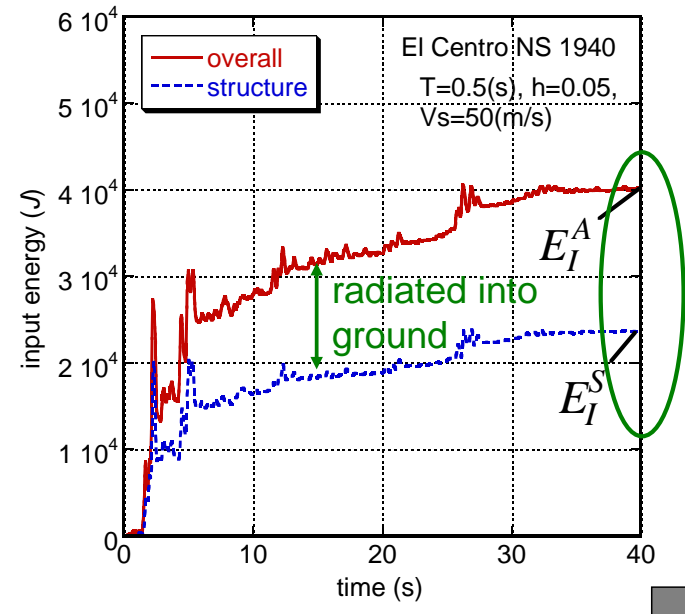

El Centro NS 1940

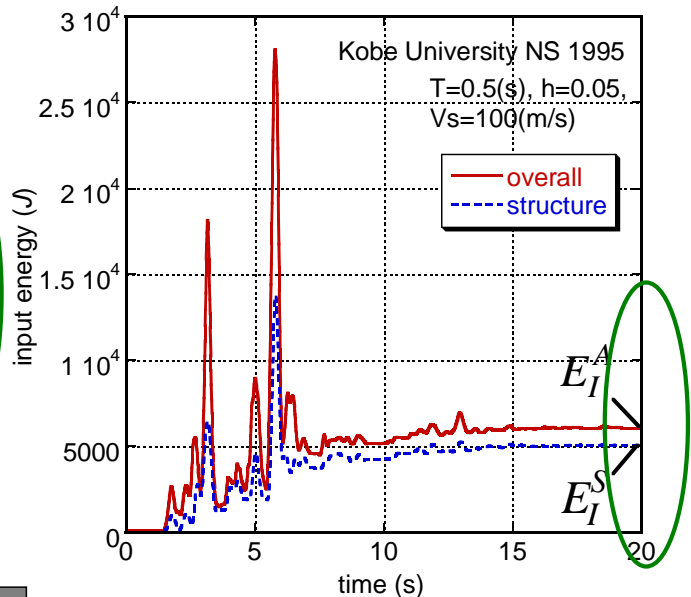

Kobe University NS 1995

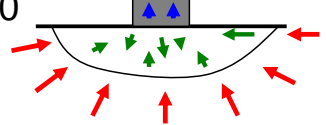

Fig.10 Earthquake input energies to overall system and structure only 

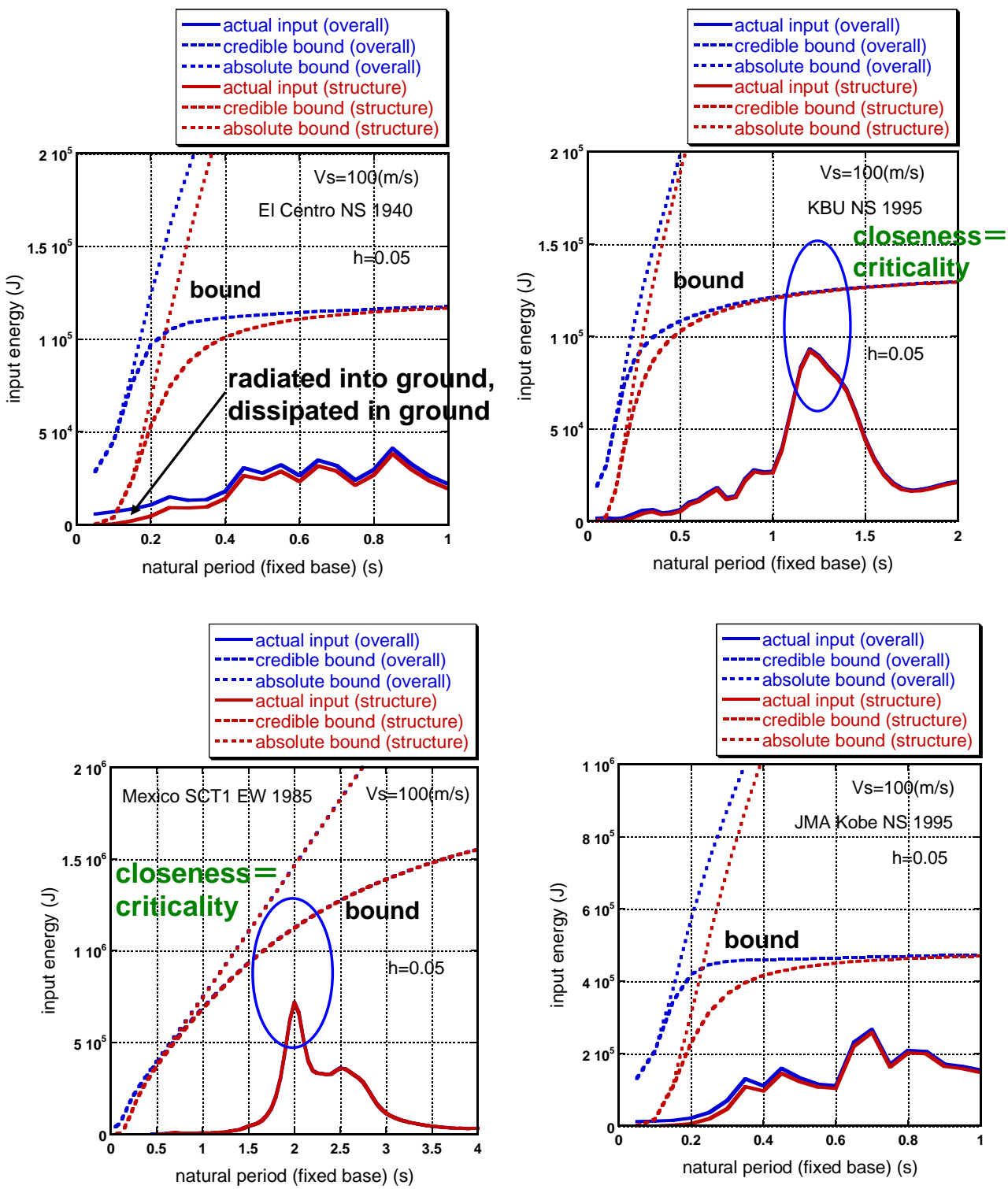

Fig.11 Credible and absolute bounds of earthquake input energies to overall system and structure only

\section{Earthquake input energy to soil-pile-structure interaction models}

The mechanism of earthquake energy input from the bedrock through the surface ground and pile is very complicated and it may be useful to investigate the energy flow using the energy transfer function (Takewaki 2005a). Fig.12 shows (i) a multiply supported soil-pile-structure model, (ii) boundary forces for evaluation of works, (iii) the shear wave profiles of Ground A and $\mathrm{B}$, (iv) the design acceleration response spectra at the bedrock (damage-limit level and safety-limit level), (v) an FEM model for comparison, (vi) damping model of the Winkler spring and (vii) soil models (stiffness reduction and damping). 


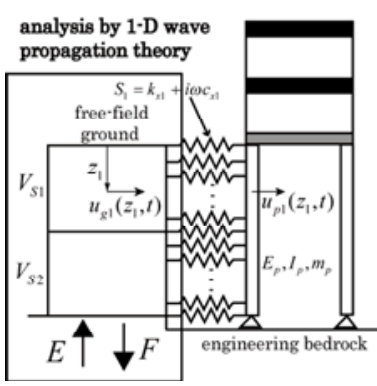

(i) Multiply-supported model

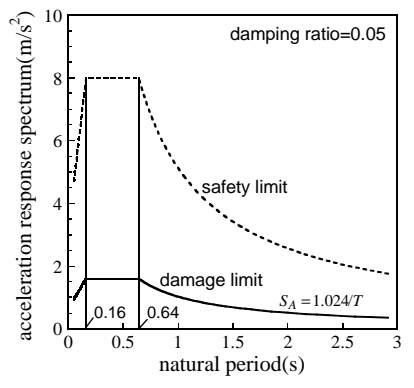

(iv) Design spectra

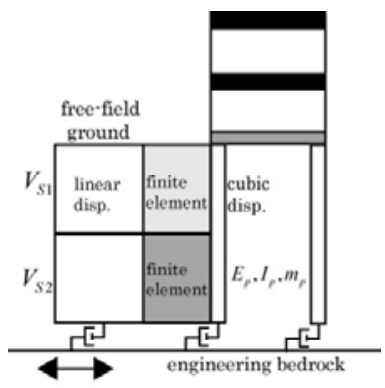

$2 E$ (v) FEM model for comparison

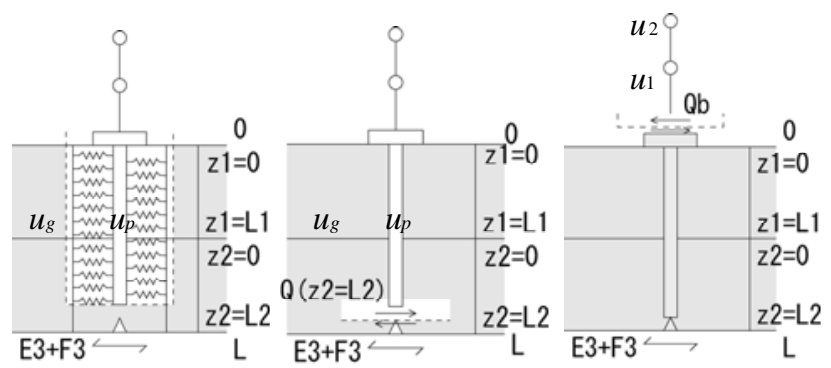

(ii) Boundary forces for evaluation of work
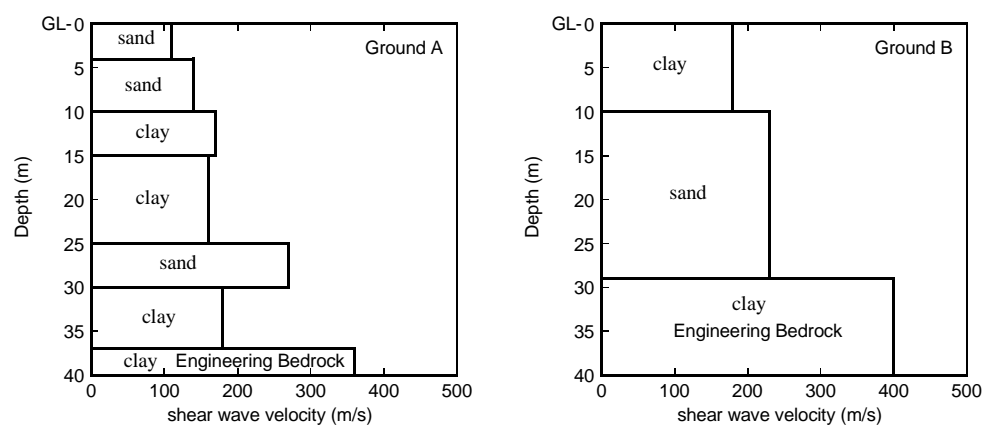

(iii) Two ground models

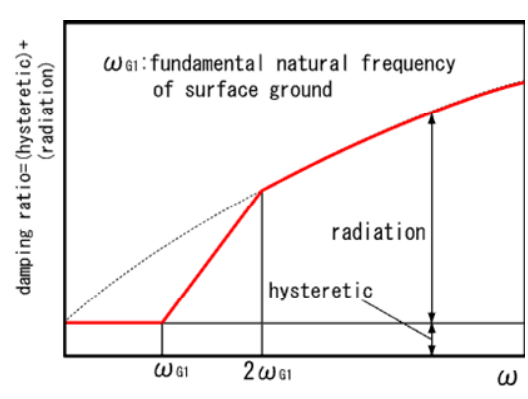

(vi) Damping of Winkler spring

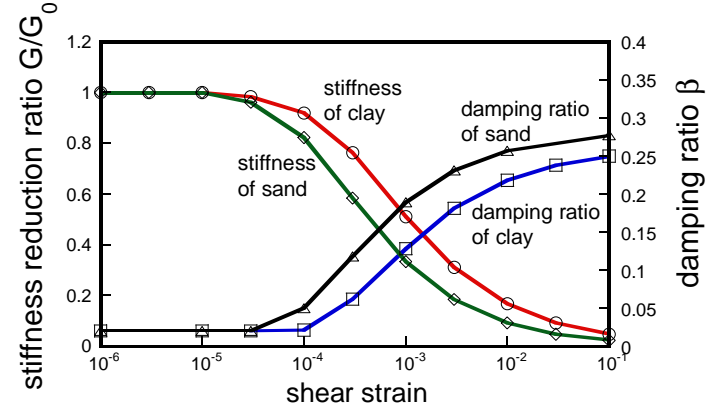

(vii) Soil model (stiffness reduction and damping)

Fig.12 Mechanism of earthquake energy input to soil-pile-structure system, (i) multiply supported soil-pile-structure model, (ii) boundary forces for evaluation of works, (iii) shear wave profiles of Ground A and B, (iv) design acceleration response spectra at the bedrock (damage-limit level and safety-limit level), (v) FEM model for comparison, (vi) damping model of the Winkler spring and (vii) soil models (stiffness reduction and damping) 

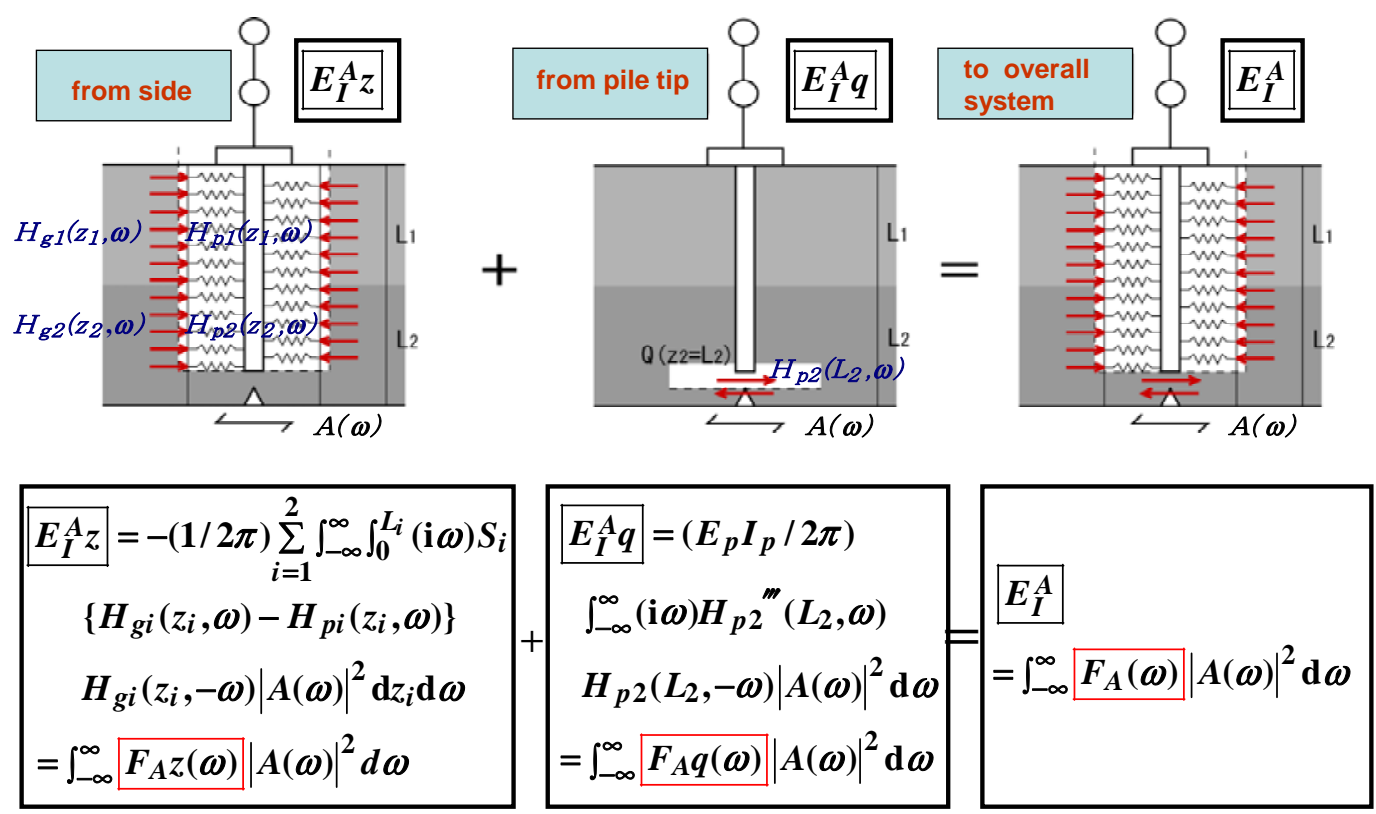

(a) Input energy to soil-pile-structure system (from side and from pile-tip)

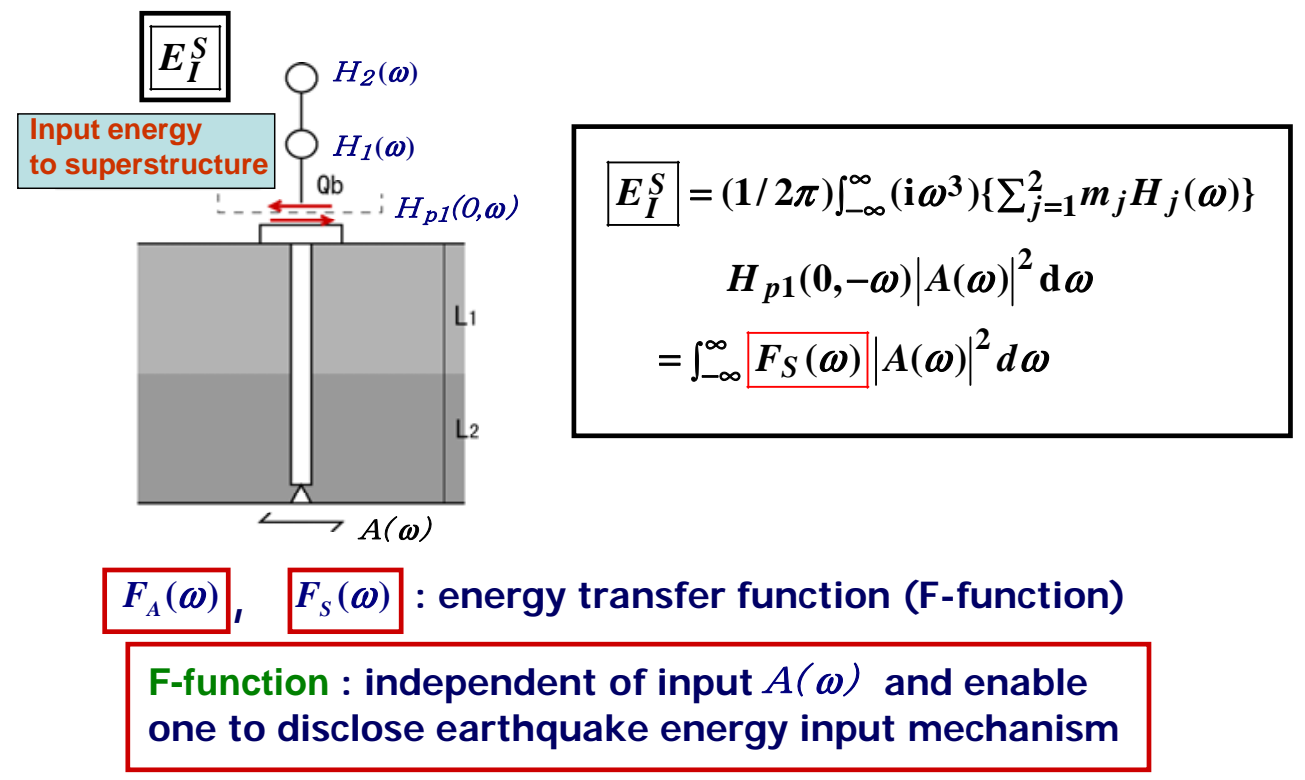

(b) Input energy to structure

Fig.13 Mechanism of earthquake energy input in terms of various subassemblages

Consider free bodies as shown in Fig.13(a) and (b). For simplicity of expression, it is assumed again that $n=n_{b}=2$. Let us define the work by the forces at the side of the surrounding soil and at the pile tip on the corresponding displacements as the input energy into the building-pile system. $H_{g i}$ and $H_{p i}$ denote the displacement transfer function for the free-field ground and the pile to the base input. In addition, $S_{i}$ is the stiffness of the Winkler soil spring and $E_{p} I_{p}$ is the pile bending stiffness. 
Figs.13(a) and (b) shows the mechanism of earthquake energy inputs to a structure-pile system in terms of various subassemblages. In Fig.13(a), the energy input from the side, from the pile-tip and from the both is explained. On the other hand, the energy input to a structure is presented in Fig.13(b).
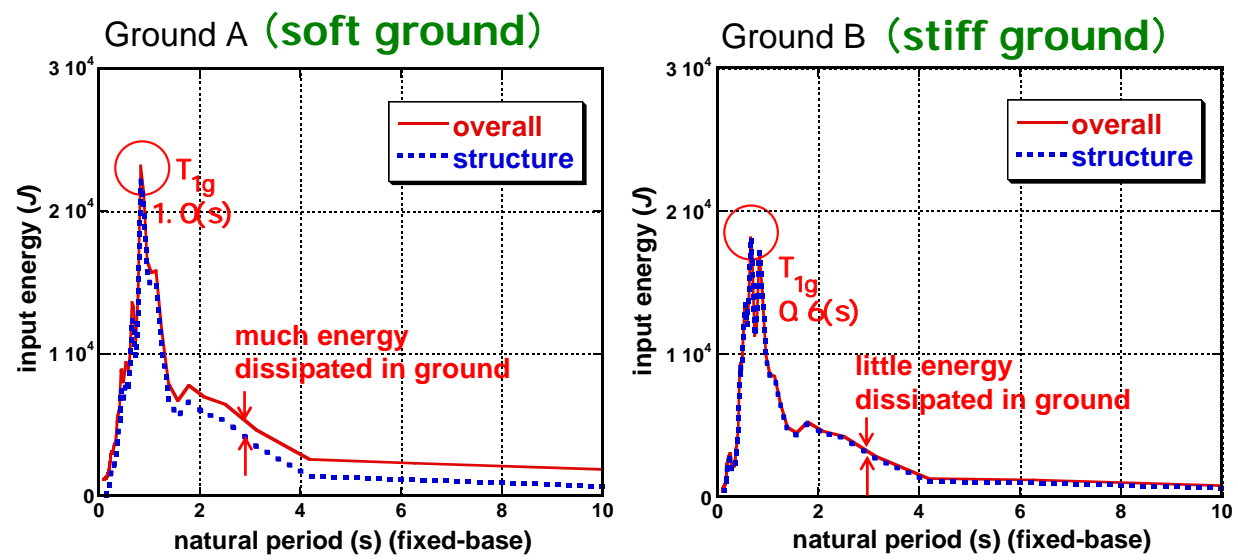

I nput energy to overall system and structure by El Centro NS (I mperial Valley 1940) ( damage-limit level input )

(a) Earthquake input energy to overall system and structure
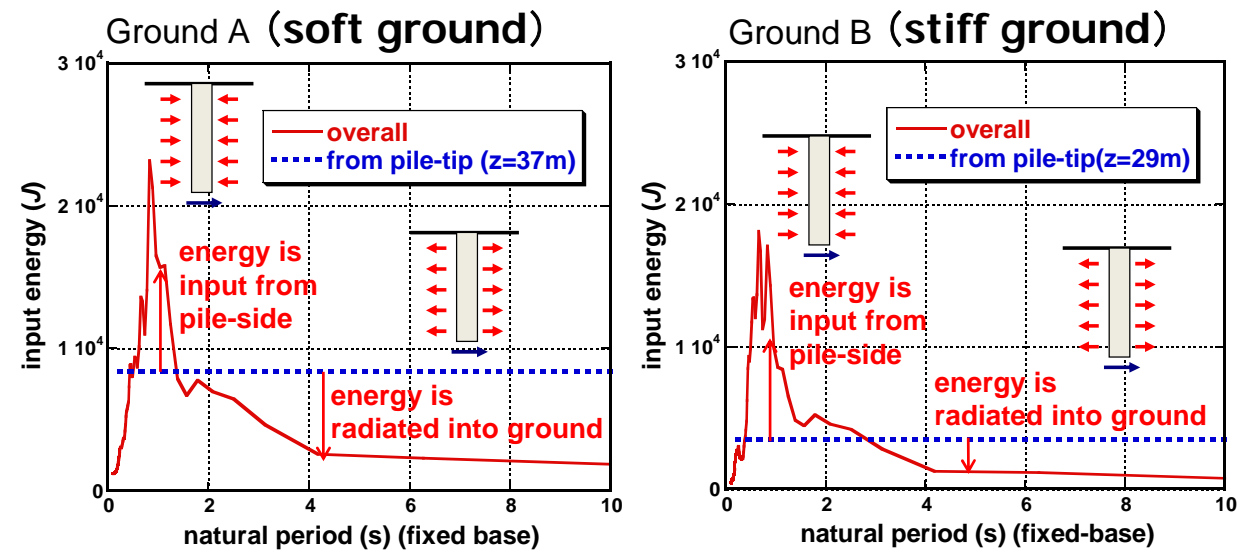

I nput energy to overall system and that from pile tip by El Centro NS (I mperial Valley 1940) (damage-limit level input )

(b) Earthquake input energy to overall system and that from pile-tip

Fig.14 Mechanism of earthquake energy input (damage-limit level motion)

The upper figure in Fig.14 shows the earthquake input energies to an overall system and a structure (damage-limit level). On the other hand, the lower figure shows the case where the energy input exists from the pile-side and the case where the energy radiation into ground exists. 

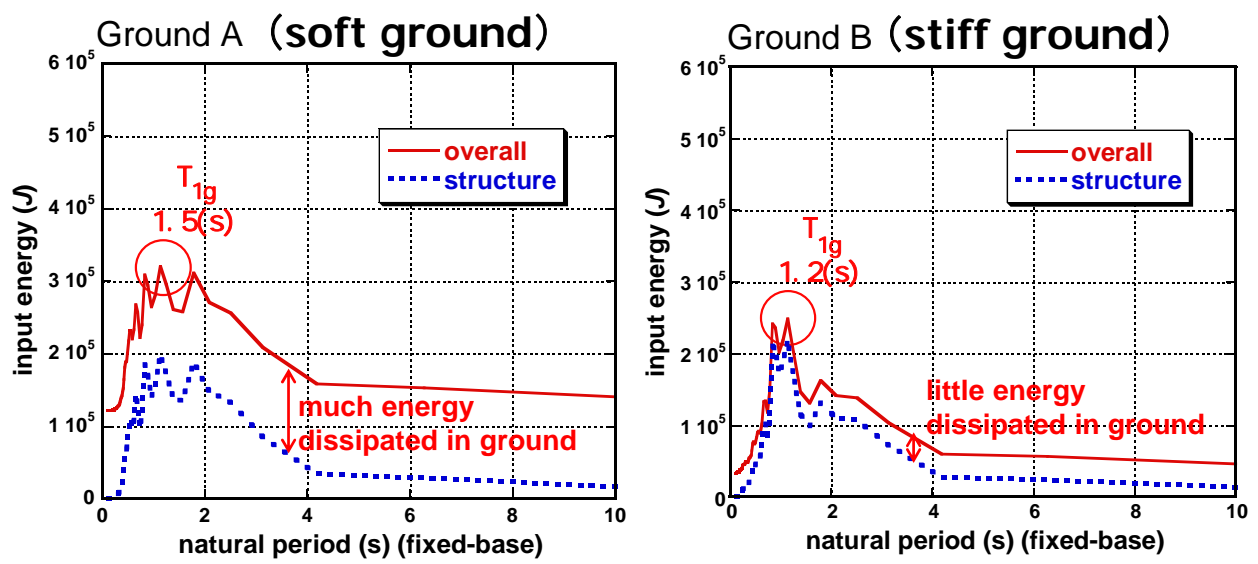

Input energy to overall system and structure by El Centro NS (Imperial Valley 1940) ( safety-limit level input)

(a) Earthquake input energy to overall system and structure
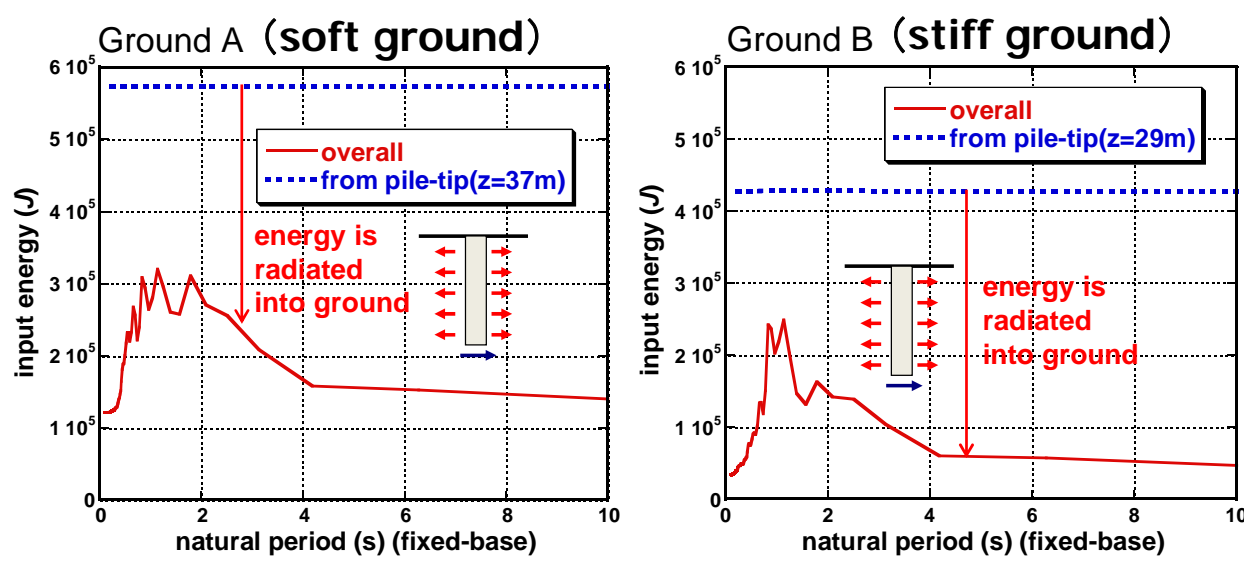

Input energy to overall system and that from pile tip by El Centro NS (Imperial Valley 1940) ( safety-limit level input )

(b) Earthquake input energy to overall system and that from pile-tip

Fig.15 Mechanism of earthquake energy input (safety-limit level motion)

The upper figure in Fig.15 shows the earthquake input energies to an overall system and a structure (safety-limit level). On the other hand, the lower figure shows the case where the energy radiation into ground exists. 

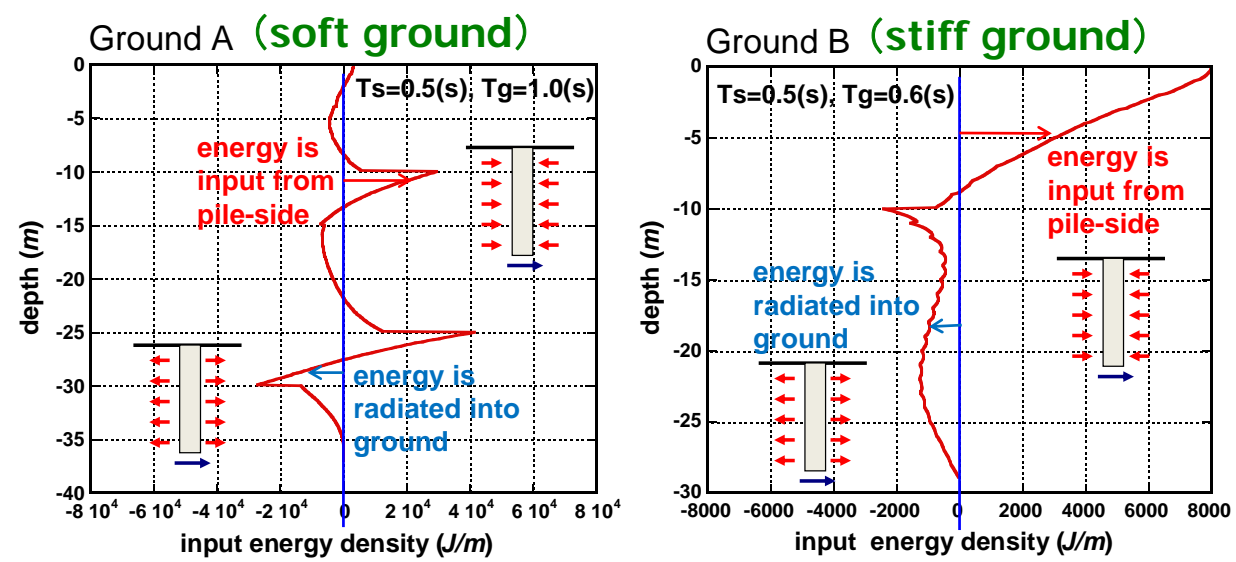

underground input energy density from side-soil (damage-limit level input)

(a) Damage-limit level input
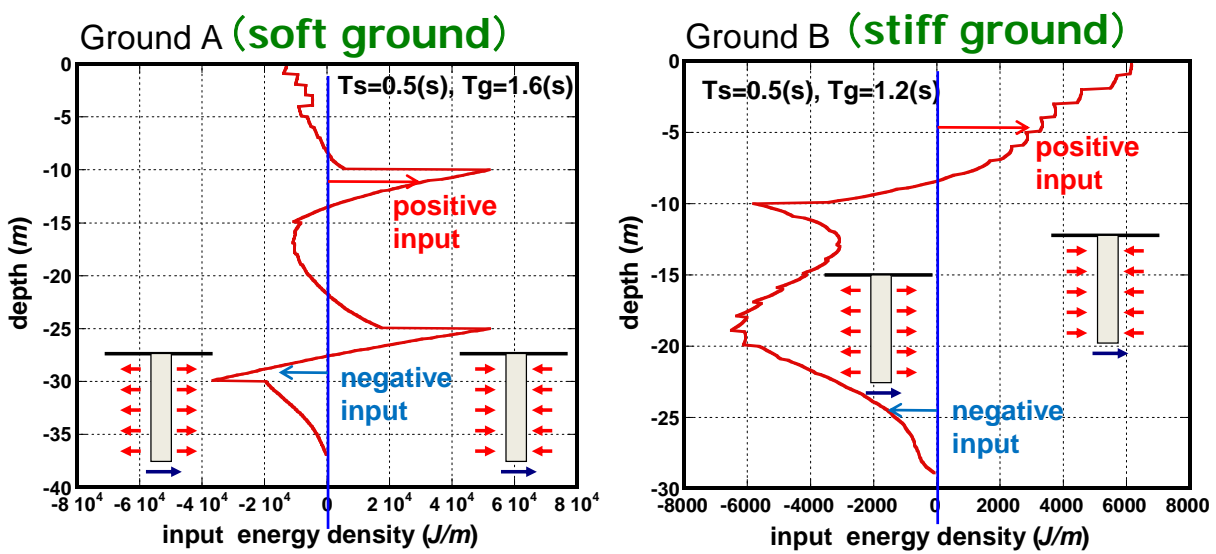

underground input energy density from side-soil (safety-limit level input)

(b) Safety-limit level input

Fig.16 Underground input energy density from side-soil

Fig.16(a), (b) show the input energy density whose integration over the pile represents the input energy from the side of the surrounding soil (Ground A and B, damage-limit level and safety-limit level).

A new evaluation method of earthquake input energy to structure-pile-soil interaction systems has been explained (Takewaki 2005a). The method is an approach in the frequency domain. The energy transfer function, which plays a key role in the input energy evaluation, is derived from the transfer functions of the structure-pile-soil interaction system to the earthquake acceleration input at the bedrock.

The introduction of the definition of two input energies, one to the overall system (structure plus pile and surrounding soil) and the other to the structure alone, is very useful in understanding the mechanism of the earthquake energy input and the effect of soil-structure interaction under various conditions of soil properties and natural period of structures on the earthquake energy input. 
The introduced input energy density whose integration over the pile represents the input energy from the side of the surrounding soil is appropriate for disclosing the energy input mechanism or energy flow in the underground.

The energy transfer function can be defined even at a point (including underground) and it is easy to understand general characteristics of the flow of the earthquake energy at the point or in the area. These characteristics in the underground depend on the soil property and its depth. It has been shown that these general characteristics can be characterized by the energy transfer function.

\section{Earthquake input energy to connected building structures}

Consider the case where multiple buildings are connected by dampers. If the natural periods of respective buildings are different and the difference of those natural periods is large, the connecting dampers absorb much energy and the energy input into the buildings becomes smaller.

Fig.17 shows passively controlled buildings with connecting dampers and mechanism of earthquake energy input. The energy transfer functions for three parts (building 1, building 2 and connecting damper) represent the mechanism of earthquake energy input to this passively controlled building (Takewaki 2007b, 2013c).

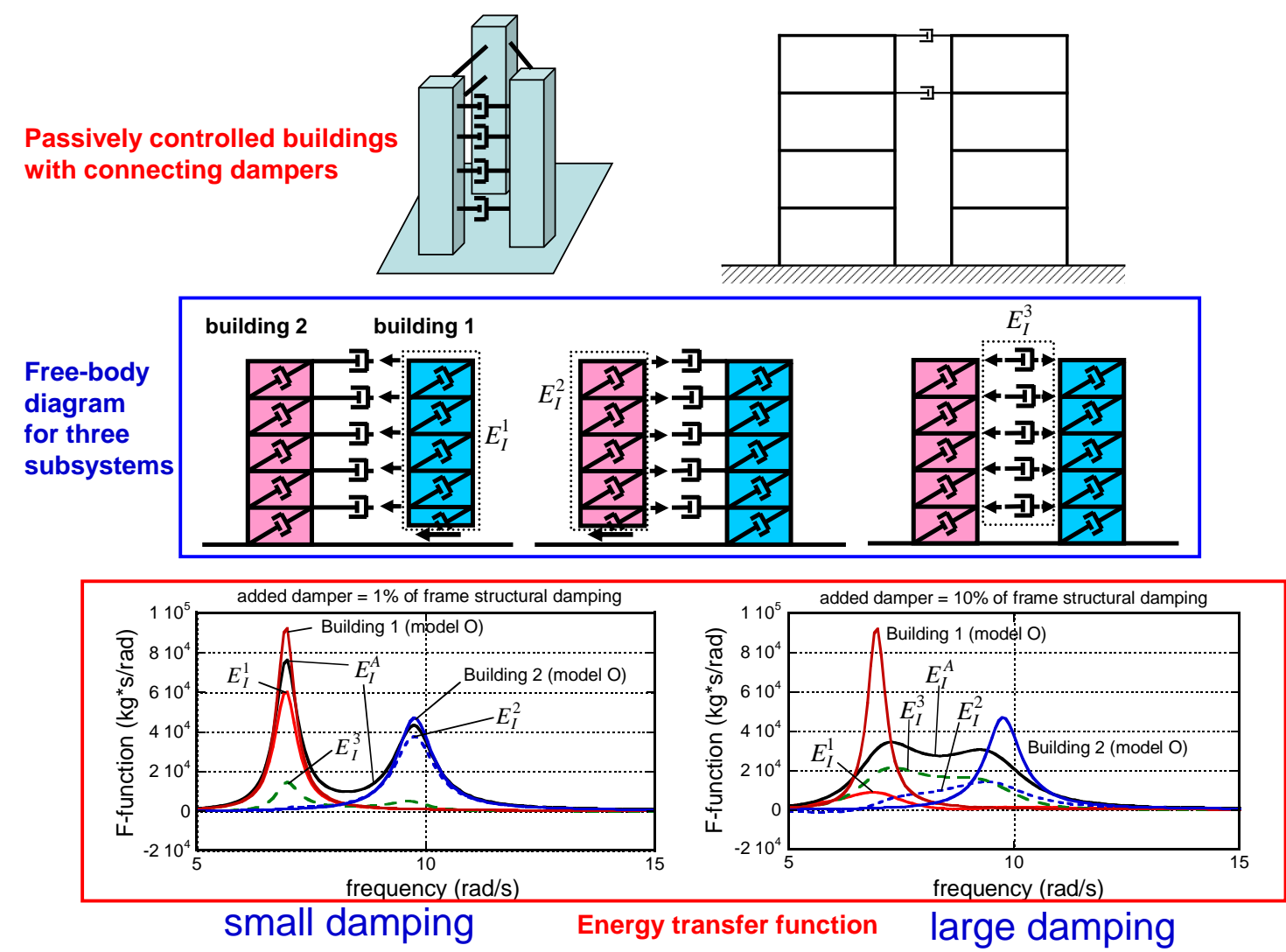

Fig.17 Passively controlled buildings with connecting dampers and mechanism of earthquake energy input 


\section{Earthquake energy input rate (probabilistic)}

The earthquake energy input rate has been introduced as an important measure of ground motion destructiveness. In an early stage, Page (1952) introduced the concept of instantaneous power spectrum. After many years, Iyama and Kuwamura (1999) developed several interesting theories on the earthquake energy input rate. While the earthquake input energy can represent the energy absorbed in a structure during a ground motion input, the earthquake energy input rate can capture the direct and instantaneous load effect of ground motions in view of producing the maximum deformation in a structure. Actually many researchers pointed out that the earthquake energy input rate may be more crucial for structures than the earthquake input energy for pulse-like near-fault ground motions (Hall et al. 1995; Iyama and Kuwamura 1999; Bozorgnia and Bertero 2003). In this section, the earthquake energy input rate is taken as a measure of criticality of ground motions (Takewaki 2006a).

The earthquake energy input rate has been a useful measure for expressing the short-period (impulsive) effect of ground motions on structures. Fig.18 shows (a) time history of earthquake input energy per unit mass, (b) energy input rate and (c) story drift for El Centro NS (Imperial Valley 1940). On the other hand, Fig.19 illustrates (a) time history of earthquake input energy per unit mass, (b) energy input rate and (c) story drift for KBU NS (Hyogoken-Nanbu 1995).

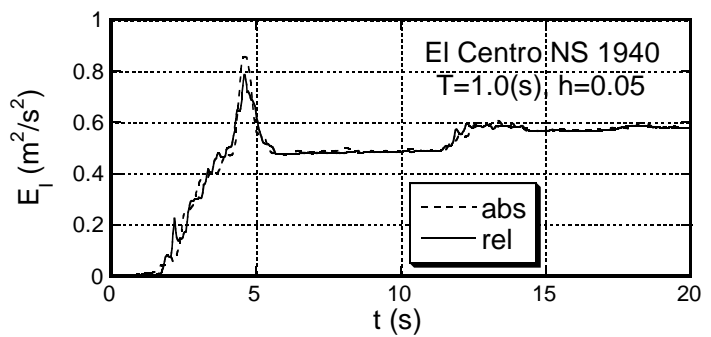

(a)

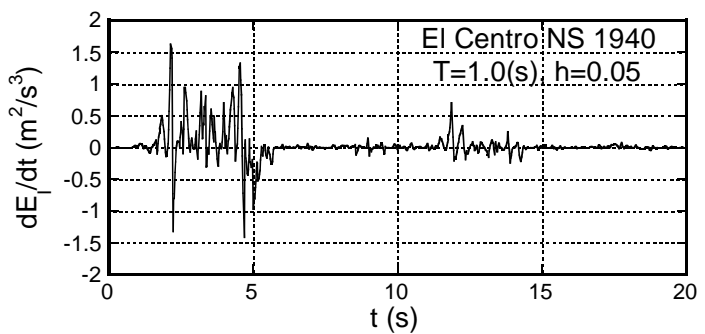

(b)

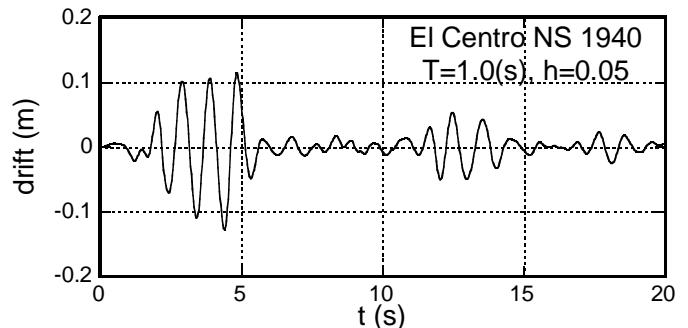

(c)

Fig.18 Example of earthquake input energy, (a) Time history of input energy per unit mass, (b) Energy input rate and (c) Story drift for El Centro NS (Imperial Valley 1940) (Takewaki 2006a) 


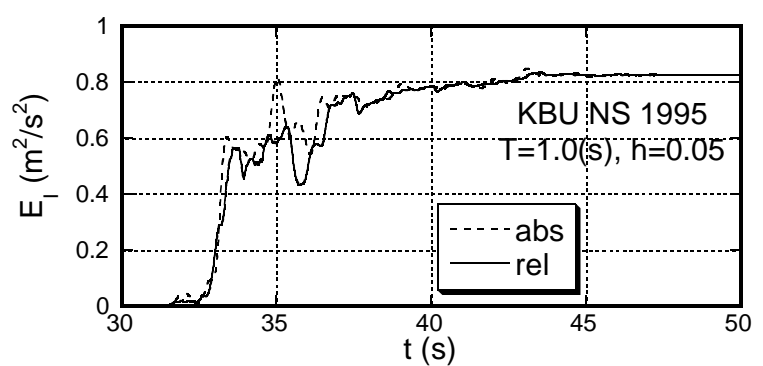

(a)

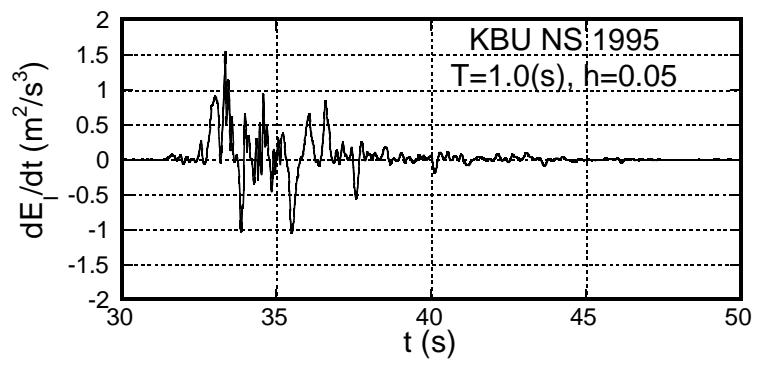

(b)

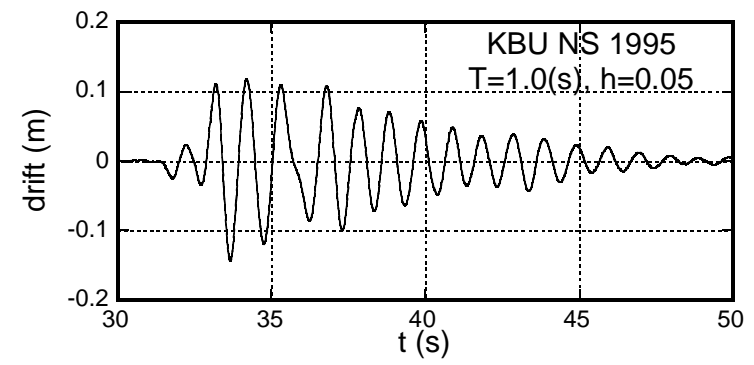

(c)

Fig.19 Example of earthquake input energy, (a) Time history of input energy per unit mass, (b) Energy input rate and (c) Story drift for KBU NS (Hyogoken-Nanbu 1995) (Takewaki 2006a)

For clear presentation of a new concept, consider a damped, linear elastic SDOF model with a mass $m$ subjected to a base acceleration $\ddot{u}_{g}(t)=c(t) w(t) \quad(c(t)$ : deterministic envelope function, $w(t)$ : stationary Gaussian process with zero mean). Let $\omega_{n}, h, \omega_{D}=\omega_{n} \sqrt{1-h^{2}}$ denote the undamped natural circular frequency, the damping ratio and the damped natural circular frequency of the model, respectively. The horizontal displacement $x(t)$ of the mass relative to the ground may then be expressed by

$$
x(t)=\int_{-\infty}^{t} g(t-\zeta) \ddot{u}_{g}(\zeta) d \zeta
$$

where $g(t)$ is the unit impulse response function in the underdamped case and is described by

$$
g(t)=-\frac{1}{\omega_{D}} e^{-h \omega_{n} t} \sin \omega_{D} t
$$

The time derivative of $g(t)$ may be obtained as 


$$
\dot{g}(t)=\frac{h}{\sqrt{1-h^{2}}} e^{-h \omega_{n} t} \sin \omega_{D} t-e^{-h \omega_{n} t} \cos \omega_{D} t
$$

It can be shown after some manipulations that the horizontal velocity $\dot{x}(t)$ of the mass relative to the ground is expressed by

$$
\dot{x}(t)=\int_{-\infty}^{t} \dot{g}(t-\zeta) \ddot{u}_{g}(\zeta) d \zeta
$$

By using the relation $\ddot{u}_{q}(t)=c(t) w(t)$ and Eq.(29), the earthquake input energy $E_{I}(t)$ (solid line in Figs.18(a), 19(a)) per unit mass to the SDOF model until time $t$ can be expressed by

$$
\begin{aligned}
E_{I}(t) & =-\int_{-\infty}^{t} \dot{x}(\tau) \ddot{u}_{g}(\tau) d \tau \\
& =-\int_{-\infty}^{t} \int_{-\infty}^{\tau} \dot{g}(\tau-\zeta) \ddot{u}_{g}(\zeta) d \zeta \ddot{u}_{g}(\tau) d \tau \\
& =-\int_{-\infty}^{t} \int_{-\infty}^{\tau} \dot{g}(\tau-\zeta) c(\zeta) w(\zeta) c(\tau) w(\tau) d \zeta d \tau
\end{aligned}
$$

The conduct of ensemble mean of Eq.(30) and substitution of the relation of the auto-correlation function of $w(t)$ with its power spectral density function $S_{w}(\omega)$ into the resulting equation lead to the following expression of mean of the earthquake input energy.

$$
\begin{aligned}
E\left[E_{I}(t)\right] & =-\int_{-\infty}^{\infty} \int_{-\infty}^{t} \int_{-\infty}^{\tau} \dot{g}(\tau-\zeta) c(\zeta) c(\tau) e^{\mathrm{i} \omega \zeta} e^{-\mathrm{i} \omega \tau} S_{w}(\omega) d \zeta d \tau d \omega \\
& =\int_{-\infty}^{\infty} G(t, \omega) S_{w}(\omega) d \omega
\end{aligned}
$$

where $G(t, \omega)$ in the integrand can be defined by

$$
G(t, \omega)=-\int_{-\infty}^{t} \int_{-\infty}^{\tau} \dot{g}(\tau-\zeta) c(\zeta) c(\tau) e^{\mathrm{i} \omega \zeta} e^{-\mathrm{i} \omega \tau} d \zeta d \tau
$$

Since the ensemble mean and the time derivative are exchangeable in this case, the mean of the energy input rate may be written from Eq. (31) as

$$
E\left[\frac{d}{d t} E_{I}(t)\right]=\int_{-\infty}^{\infty} \frac{\partial}{\partial t}[G(t, \omega)] S_{w}(\omega) d \omega
$$

The rearrangement of Eq.(32) provides

$$
G(t, \omega)=-\int_{-\infty}^{t} c(\tau) e^{-\mathrm{i} \omega \tau}\left(\int_{-\infty}^{\tau} \dot{g}(\tau-\zeta) c(\zeta) e^{\mathrm{i} \omega \zeta} d \zeta\right) d \tau
$$

The time derivative of the function $G(t, \omega)$ may then be expressed by 


$$
\frac{\partial}{\partial t}[G(t, \omega)]=-c(t) e^{-\mathrm{i} \omega t}\left(\int_{-\infty}^{t} \dot{g}(t-\zeta) c(\zeta) e^{\mathrm{i} \omega \zeta} d \zeta\right)
$$

Since the mean energy input rate $E\left[d E_{I}(t) / d t\right]$ and the PSD function $S_{w}(\omega)$ are real numbers, only the real part of $\partial[G(t, \omega)] / \partial t$ is meaningful in the evaluation of $E\left[d E_{I}(t) / d t\right]$. Eq.(33) may therefore be reduced to

$$
E\left[\frac{d}{d t} E_{I}(t)\right]=\int_{-\infty}^{\infty} \operatorname{Re}[\partial G(t, \omega) / \partial t] S_{w}(\omega) d \omega
$$

The critical input can be derived by treating $\operatorname{Re}[\partial G(t, \omega) / \partial t]$ as a key function.

\section{Earthquake energy input rate (deterministic)}

The ensemble mean of earthquake energy input rate to an SDOF model has been treated in Section 10 in a probabilistic framework. In this section, a deterministic expression of earthquake energy input rate to an MDOF model is introduced (Yamamoto et al. 2011).

Consider a base-isolated building as shown in Fig.20. Let $\mathbf{u}(t), \mathbf{M}, \mathbf{1}$ denote the horizontal floor displacement vector, the mass matrix and the vector consisting of unity only. The earthquake input energy to this model until time $t$ may be expressed by

$$
E_{I}(t)=-\int_{0}^{t} \dot{\mathbf{u}}(\tau)^{T} \mathbf{M} 1 \ddot{u}_{g}(\tau) d \tau
$$

Let us define a modified ground motion $\hat{\ddot{u}}_{g}(\tau ; t)$ at time $\tau$ which has the same component until time $t$ and a null component after time $t$ (see Fig.21, Takewaki 2005b). This quantity is called 'the truncated ground motion'. The response velocity at time $\tau$ corresponding to $\hat{\ddot{u}}_{g}(\tau ; t)$ is denoted by $\hat{\hat{\dot{u}}}(\tau ; t)$. The Fourier transforms of $\hat{\ddot{u}}_{g}(\tau ; t)$ and $\hat{\dot{\mathbf{u}}}(\tau ; t)$ are expressed by $\hat{\ddot{U}}_{g}(\omega ; t)$ and $\hat{\dot{\mathbf{U}}}(\omega ; t)$, respectively. From its definition, it is found that $\hat{\tilde{U}}_{g}\left(\omega ; t_{0}\right)=\ddot{U}_{g}(\omega)$.

By introducing the truncated ground motion $\hat{\ddot{u}}_{g}(\tau ; t)$ and the corresponding velocity response $\hat{\dot{\mathbf{u}}}(\tau ; t)$ and extending the integration limits, Eq.(37) can be rewritten as

$$
E_{I}(t)=-\int_{-\infty}^{\infty} \hat{\dot{\mathbf{u}}}(\tau ; t)^{T} \mathbf{M} 1 \hat{\ddot{u}}_{g}(\tau ; t) d \tau
$$

Application of the Fourier and inverse Fourier transformations (Lyon 1975; Kuwamura et al. 1994; Ordaz et al. 2003; Takewaki 2004a, b) to Eq.(38) may be reduced to

$$
\begin{aligned}
E_{I}(t) & =-\int_{-\infty}^{\infty} \frac{1}{2 \pi} \int_{-\infty}^{\infty} \hat{\dot{\mathbf{U}}}(\omega ; t)^{T} e^{\mathrm{i} \omega \tau} \mathbf{M} \mathbf{1} \hat{\ddot{u}}_{g}(\tau ; t) d \omega d \tau \\
& =\frac{1}{2 \pi} \int_{-\infty}^{\infty} \mathrm{i} \omega \mathbf{1}^{T} \mathbf{M}^{T} \mathbf{A}^{-1} \hat{\tilde{U}}_{g}(\omega ; t) \mathbf{M} \mathbf{1} \hat{\tilde{U}}_{g}(-\omega ; t) d \omega \\
& =\int_{0}^{\infty}\left|\hat{\tilde{U}}_{g}(\omega ; t)\right|^{2} F(\omega) d \omega
\end{aligned}
$$


In Eq.(39) $\left|\hat{\tilde{U}}_{g}(\omega ; t)\right|^{2}$ is referred to as the squared Fourier amplitude spectrum (SFAS) and plays a principal role in the present formulation. In the derivation of Eq.(39), the relation $\hat{\mathbf{U}}(\omega ; t)=-\mathbf{i} \omega \mathbf{A}^{-1} \mathbf{M} 1 \hat{\tilde{U}}_{g}(\omega ; t)$ is used and the function $F(\omega)$ is defined by

$$
F(\omega) \equiv \operatorname{Re}\left[\mathrm{i} \omega \mathbf{1}^{T} \mathbf{M}^{T} \mathbf{A}^{-1} \mathbf{M} \mathbf{1}\right] / \pi
$$

Since $\hat{\tilde{U}}_{g}\left(\omega ; t_{0}\right)=\ddot{U}_{g}(\omega)$ from its definition, it follows that

$$
E_{I}\left(t_{0}\right)=\int_{0}^{\infty}\left|\ddot{U}_{g}(\omega)\right|^{2} F(\omega) d \omega
$$

From Eq.(39), the earthquake energy input rate $d E_{I}(t) / d t$ may be expressed by

$$
\frac{d E_{I}(t)}{d t}=\int_{0}^{\infty}\left(d\left|\hat{\tilde{U}}_{g}(\omega ; t)\right|^{2} / d t\right) F(\omega) d \omega
$$

The expression $d\left|\hat{\ddot{U}}_{g}(\omega ; t)\right|^{2} / d t$ is equivalent to 'the instantaneous power spectrum' introduced and discussed by Page (1952).

Numerical examples of the deterministic earthquake energy input rate for a base-isolated 10-story shear building model (BI building or BI system) are presented. The story stiffnesses of the building are determined so that the 10-story shear building model with fixed-base has the fundamental natural periods of 1.0(s) and the lowest eigenmode of the model with fixed-base is straight (inverted triangle). Then the lowest eigenmode (super-structural part) of the BI building is not straight. This procedure is based on the inverse problem approach (Nakamura and Yamane 1986). It is also assumed that the damping matrix of the super-structure with fixed base is proportional to the stiffness matrix of the super-structure and the damping ratio in the lowest mode of the super-structure with fixed base is 0.02. The stiffness $k$ and damping coefficient $c$ of the BI system have been determined so that the fundamental natural period of the BI building is 5.3(s) (see Takewaki 1998 for hybrid inverse problems for rigid building stiffnesses) and the damping ratio of the BI rigid building model is 0.2.

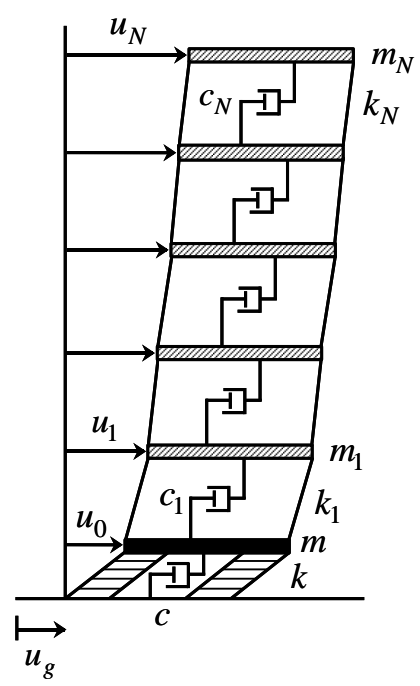

Fig.20 N-story shear building model supported by base-isolation system 


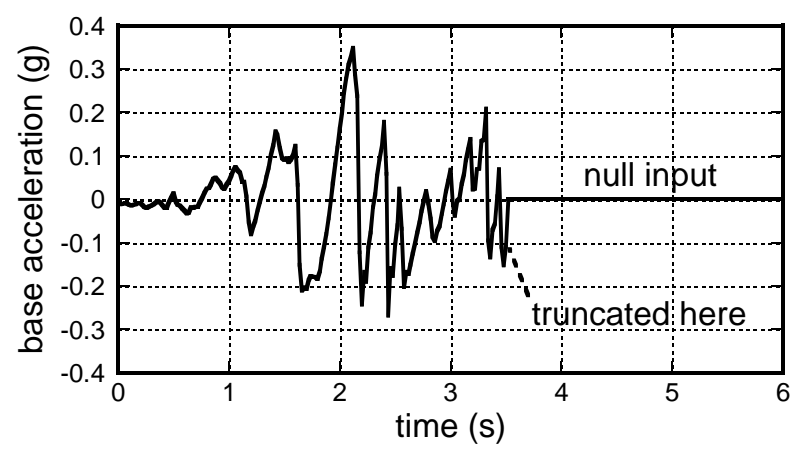

Fig.21 Truncated ground motion

\section{[Example (model of SFAS of truncated ground motion)]}

Since the concept of SFAS is somewhat complicated and it seems beneficial to consider example models, its model is constructed. An example of SFAS $\left|\hat{\tilde{U}}_{g}(\omega ; t)\right|^{2}$ of truncated ground motions can be expressed by

$$
\left|\hat{\tilde{U}}_{g}(\omega ; t)\right|^{2}=\left\{\begin{array}{l}
2 \pi t \cdot S_{u}(\omega, t)=2 \pi t \cdot a\left(e^{-b_{1} t}-e^{-b_{2} t}\right) S(\omega) \quad\left(0 \leq t \leq t_{0}\right) \\
2 \pi t_{0} \cdot S_{u}\left(\omega, t_{0}\right)=2 \pi t_{0} \cdot a\left(e^{-b_{1} t_{0}}-e^{-b_{2} t_{0}}\right) S(\omega) \quad\left(t \geq t_{0}\right)
\end{array}\right.
$$

where $t_{0}$ is the terminal time (duration) of the input ground motion and the frequency function $S(\omega)$ denotes

$$
S(\omega)=\left\{\frac{\Omega^{4}+4 \zeta^{2} \Omega^{2} \omega^{2}}{\left[\omega^{2}-\Omega^{2}\right]^{2}+4 \zeta^{2} \Omega^{2} \omega^{2}}\right\} S_{0}
$$

In Eq.(44), $\Omega$ and $\zeta$ are the predominant circular frequency and damping parameter. Furthermore $S_{0}$ is a constant value.

The short period models 1 and 2 with the duration=40(s) (predominant period=0.6 and $0.8(\mathrm{~s})$ ) and long period models $1-3$ with the duration=180(s) (predominant period=3.0, 5.3 and 8.0(s)) are taken into account.

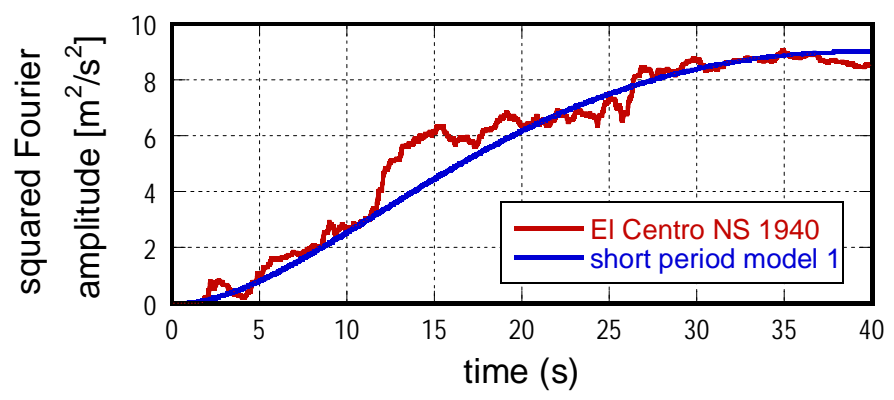

Fig.22 Time history of SFAS at 18(rad/s) of truncated ground motions extracted from El Centro NS 1940 and the corresponding time history of short period model 1 


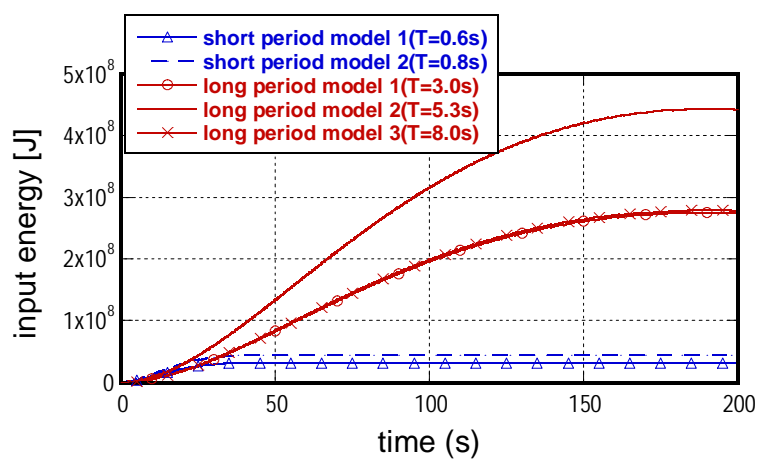

Fig.23 Time histories of input energy for various ground motion models

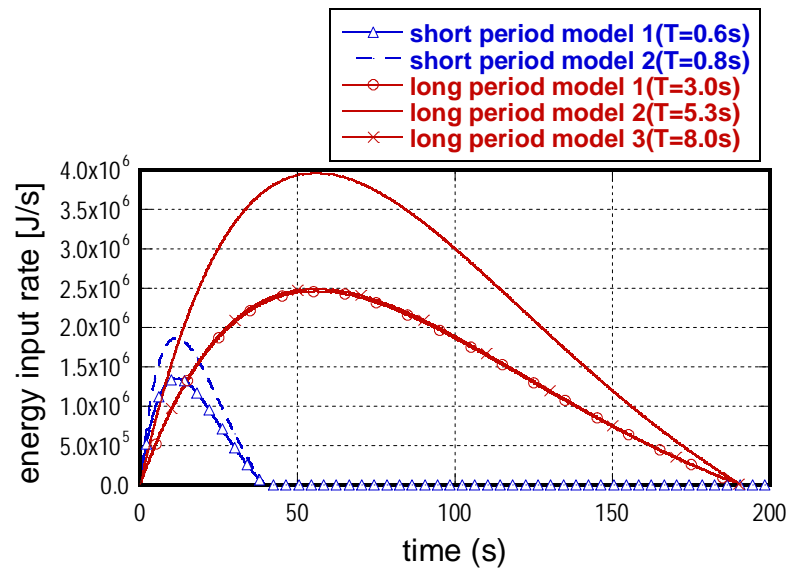

Fig.24 Time histories of energy input rate for various ground motion models

Fig.22 shows the time history of SFAS at 18(rad/s) of truncated ground motions extracted from El Centro NS 1940 and the corresponding time history of short period model 1. Fig.23 presents the time histories of input energy for various ground motion models. On the other hand, Fig.24 illustrates the time histories of energy input rate for various ground motion models. It can be observed from Figs.23 and 24 that the long period model 2 (predominant period=5.3(s)) exhibits the largest input energy and energy input rate to this base-isolated building with the fundamental natural period=5.3(s).

\section{Conclusions}

The following conclusions have been obtained.

(1) The earthquake input energy to a system (superstructure, soil-structure system, soil-pile-structure system, etc.) can be defined as a work done by boundary forces on its system. While the formulation in the time domain can be applied to both linear and nonlinear systems, that in the frequency domain is applicable only to linear and equivalently linear systems. The formulation in the frequency domain has some advantages, e.g. the verification of the constant input energy criterion, the investigation of energy input mechanisms through the energy transfer function $F(\omega)$.

(2) The energy transfer function $F(\omega)$ characterizing the earthquake input energy in the 
frequency domain to a damped linear elastic SDOF system has been proved by the Residue theorem to be of an equi-area property irrespective of natural period and damping ratio. This property guarantees that, if the Fourier amplitude spectrum of a ground acceleration is uniform with respect to frequency, the constancy of the input energy holds strictly. Otherwise, its constancy is not guaranteed. The constancy of the earthquake input energy is directly related to the constancy of 'the Fourier amplitude spectrum' of the ground acceleration with respect to frequency, not the constancy of the velocity response spectrum with respect to natural period.

(3) The manipulation of the earthquake input energy in the time domain is suitable for the evaluation of the time history of the input energy, especially for non-linear systems. Dual use of the frequency-domain and time-domain techniques may be preferable in the sophisticated seismic analysis of structures for more robust design.

(4) A critical excitation method has been formulated which has the earthquake input energy as a new measure of criticality and has acceleration and/or velocity constraints (the time integral of a squared ground acceleration and the time integral of a squared ground velocity). No mathematical programming technique is needed in this method and structural engineers can find the solution, i.e. upper bounds of earthquake input energy, without difficulty.

(5) A method of evaluation of earthquake input energy to soil-structure interaction systems has been explained. The method is based on the formulation in the frequency domain. Because the inertial interaction, i.e. foundation impedance, and the kinematic interaction, i.e. effective input motion, are described by frequency-dependent functions, the present formulation based on the frequency domain analysis is appropriate and effective.

(6) A new method for evaluating the earthquake input energy to structure-pile interaction systems has been developed. The method is also an approach in the frequency domain. The energy transfer function, which plays a key role in the input energy evaluation, is derived from the transfer functions of the structure-pile interaction system to the earthquake acceleration input at the bedrock. The introduction of the definition of two input energies, one to the overall system (structure plus pile and surrounding soil) and the other to the structure alone, is very useful in understanding the mechanism of the earthquake energy input and the effect of soil-structure interaction under various conditions of soil properties and natural period of structures on the earthquake energy input.

(7) The earthquake energy input rate is a useful measure for expressing the short-period (impulsive) effect of ground motions on structures.

(8) The energy input to structures consists of the energy dissipated by hysteretic deformation and that by viscous damping. The excessive dependence on the former mechanism leads to unrepairable states of structures which should be avoided from the viewpoint of sustainability of building structures and cities. The measure of energy is appropriate from the viewpoint of total management of buildings in a sustainable city.

\section{Acknowledgements}

Part of the present work is supported by the Grant-in-Aid for Scientific Research of Japan Society for the Promotion of Science (No.20656086, 21360267, 24246095). This support is greatly appreciated. 


\section{References}

Akiyama, H. (1985). Earthquake resistant limit-state design for buildings. University of Tokyo Press, Tokyo, Japan.

Arias, A. (1970). A measure of earthquake intensity. In Seismic design for nuclear power plants (Ed. R.J.Hansen), The MIT Press, Cambridge, MA, 438-469.

Berg, G.V., and Thomaides T.T. (1960). Energy consumption by structures in strong-motion earthquakes. Proc. of the 2nd World Conf. on Earthquake Engineering, Tokyo and Kyoto, 681-696.

Bozorgnia, Y, and Bertero, V.V. (2003). Damage spectra: characteristics and applications to seismic risk reduction. J. Struct. Engrg., ASCE, 129(10), 1330-1340.

Choi, H, and Kim, J (2006). Energy-based design of buckling-restrained braced frames using hysteretic energy spectrum. Eng. Struct., 28, 304-311.

Christopoulos, C. and Filiatrault, A. (2006). Principles of passive supplemental damping and seismic isolation, IUSS Press, Pavia, Italy.

Drenick, R.F. (1970). Model-free design of aseismic structures. J. Engineering Mechanics Division, ASCE, 96(EM4), 483-493.

Fajfar, P., and Vidic, T. (1994). Consistent inelastic design spectra: hysteretic and input energy. Earthquake Engineering and Structural Dynamics, 23(5), 523-537.

Fujita, K. and Takewaki, I. (2011). Sustainable building design under uncertain structuralparameter environment in seismic-prone countries, Sustainable Cities and Society, 1(3), 142-151.

Goel, S.C., and Berg, G.V. (1968). Inelastic earthquake response of tall steel frames. J. Structural Division, ASCE, 94, 1907-1934.

Hall, J.F., Heaton, T.H., Halling, M.W. and Wald, D.J. (1995). Near-source ground motion and its effects on flexible building, Earthquake Spectra; 11(4), 569-605.

Housner, G.W. (1956). Limit design of structures to resist earthquakes. Proc. of the First World Conference on Earthquake Engineering, Berkeley, CA, 5:1-11.

Housner, G.W. (1959). Behavior of structures during earthquakes. J. Engineering Mechanics Div., ASCE, 85(4), 109-129.

Housner, G.W. (1975). Measures of severity of earthquake ground shaking. Proc. of the US National Conf. on Earthquake Engineering, Ann Arbor, Michigan, 25-33.

Housner, G.W., and Jennings, P.C. (1975) The capacity of extreme earthquake motions to damage structures. Structural and geotechnical mechanics: A volume honoring N.M.Newmark edited by W.J. Hall, 102-116, Prentice-Hall Englewood Cliff, NJ.

Hudson, D.E. (1962). Some problems in the application of spectrum techniques to strong-motion earthquake analysis. Bulletin of Seismological Society of America, 52, 417-430.

Iyama, J., and Kuwamura, H. (1999). Application of wavelets to analysis and simulation of earthquake motions. Earthquake Engrg. Struct. Dyn., 28: 255-272.

Kalkan, E, Kunnath, SK (2008). Relevance of absolute and relative energy content in seismic evaluation of structures. Adv. Struct. Eng., 11(1), 1-18.

Khashaee, P (2004). Damage-based seismic design of structures. Earthquake Spectra 21(2):371-387.

Kishida, A. and Takewaki, I. (2006). Exact higher-order sensitivity and variation of earthquake energy input in soil-structure interaction system, Advances in Structural Engineering, 9(5), 653-669.

Kishida, A. and Takewaki, I. (2007). Analysis of earthquake energy input in soil-pile-structure system with uncertain soil parameter, Advances in Structural Engineering, 10(3), 


\section{9-244.}

Kuwamura, H., Kirino, Y., and Akiyama, H. (1994). Prediction of earthquake energy input from smoothed Fourier amplitude spectrum. Earthquake Engrg. Struct. Dyn., 23, 1125-1137.

Lang, Z.Q., Guo, P.F. and Takewaki, I. (2013). Output frequency response function based design of additional nonlinear viscous dampers for vibration control of multi-degree-of-freedom systems, Journal of Sound and Vibration, 332(19), 4461-4481.

Leger, P., and Dussault, S. (1992). Seismic-energy dissipation in MDOF structures. J. Structural Engineering, ASCE, 118(5) 1251-1269.

Lyon, R.H. (1975). Statistical energy analysis of dynamical systems, The MIT Press, Cambridge, MA.

Mahin, S.A., and Lin, J. (1983). Construction of inelastic response spectrum for single-degreeof-freedom system. Report No. UCB/EERC-83/17, Earthquake Engineering Research Center, Univ. of California, Berkeley, CA.

Moustafa A (2011). Damage-based design earthquake loads for SDOF inelastic structures. Journal of Structural Engineering (ASCE) 137(3):456-467.

Moustafa, A. and Takewaki, I. (2009). The use of probabilistic and deterministic measures to identify unfavorable earthquake records, Journal of Zhejiang University-SCIENCE A, 10(5), 619-634.

Moustafa, A. and Takewaki, I. (2010). Deterministic and probabilistic representation of near-field pulse-like ground motion, Soil Dyn. Earthquake Engrg., 30(5), 412-422.

Moustafa, A., Ueno, K. and Takewaki, I. (2010). Critical earthquake loads for SDOF inelastic structures considering evolution of seismic waves, Earthquakes and Structures, 1(2), 147-162.

Murase, M., Tsuji, M. and Takewaki, I. (2013). Smart passive control of buildings with higher redundancy and robustness using base-isolation and inter-connection, Earthquakes and Structures, 4(6), 649-670.

Nakamura T, Yamane T. (1986). Optimum design and earthquake-response constrained design for elastic shear buildings. Earthquake Engrg. Struct. Dyn. 14: 797-815.

Ordaz, M., Huerta, B., and Reinoso, E. (2003). Exact computation of input-energy spectra from Fourier amplitude spectra, Earthquake Engrg. Struct. Dyn., 32, 597-605.

Page, C.H. (1952). Instantaneous power spectra. J. Applied Physics, 23(1), 103-106.

Riddell, R., and Garcia, J.E. (2001). Hysteretic energy spectrum and damage control, Earthquake Engrg. Struct. Dyn., 30, 1791-1816.

Soong, T.T. and Dargush, G.F. (1997). Passive energy dissipation systems in structural engineering, John Wiley \& Sons, Chichester, UK.

Takewaki I. (1998). Hybrid inverse eigenmode problem for a shear building supporting a finite-element subassemblage. J. Vibration Control 4(4): 347-360.

Takewaki, I. (2001a). A new method for nonstationary random critical excitation. Earthquake Engrg. Struct. Dyn., 30(4), 519-535.

Takewaki, I. (2001b). Probabilistic critical excitation for MDOF elastic-plastic structures on compliant ground. Earthquake Engrg. Struct. Dyn., 30(9), 1345-1360.

Takewaki, I. (2002a). Critical excitation method for robust design: A review. J. Structural Engineering, ASCE, 128(5), 665-672.

Takewaki, I. (2002b). Robust building stiffness design for variable critical excitations. $J$. Structural Engineering, ASCE, 128(12) 1565-1574.

Takewaki, I. (2004a) Frequency domain modal analysis of earthquake input energy to highly damped passive control structures, Earthquake Engrg. Struct. Dyn., 33(5), 575-590. 
Takewaki, I. (2004b). Bound of earthquake input energy, J. Structural Engineering, ASCE, 130(9), 1289-1297.

Takewaki, I. (2005a). Frequency domain analysis of earthquake input energy to structure-pile systems, Engineering Structures, 27(4), 549-563.

Takewaki, I. (2005b). Bound of earthquake input energy to soil-structure interaction systems, Soil Dyn. Earthquake Engrg., 25(7-10), 741-752.

Takewaki, I. (2005c). A comprehensive review of seismic critical excitation methods for robust design, Advances in Structural Engineering, 8(4), 349-363.

Takewaki, I. (2005d) Uncertain-parameter sensitivity of earthquake input energy to base-isolated structure. Structural Engineering and Mechanics, 20(3), 347-362.

Takewaki, I. (2006a). Probabilistic critical excitation method for earthquake energy input rate, $J$. Engineering Mechanics, ASCE, 132(9), 990-1000.

Takewaki, I. (2006b) Worst-case analysis for earthquake energy input rate in SDOF and MDOF structures, Advances in Structural Engineering, 9(3), 361-375.

Takewaki, I. (2006c). Critical excitation methods in earthquake engineering, Elsevier.

Takewaki, I. (2007a). Closed-form sensitivity of earthquake input energy to soil-structure interaction system, J. Engineering Mechanics, ASCE, 133(4), 389-399.

Takewaki, I. (2007b). Earthquake input energy to two buildings connected by viscous dampers, J. Structural Engineering, ASCE, 133(5), 620-628.

Takewaki, I. (2009). Building control with passive dampers: -Optimal performance-based design for earthquakes-, John Wiley \& Sons Ltd. (Asia).

Takewaki, I. (2013a). Critical excitation methods in earthquake engineering, Second Edition, Elsevier.

Takewaki, I. (2013b). Toward greater building earthquake resilience using concept of critical excitation: a review, Sustainable Cities and Society, 9, 39-53.

Takewaki, I. (2013c). Fundamental properties of earthquake input energy on single and connected building structures, in "New trends in seismic design of structures" edited by N.D. Lagaros, Y. Tsompanakis \& M. Papadrakakis, Saxe-Coburg Publisher.

Takewaki, I. and Fujita, K. (2009). Earthquake input energy to tall and base-isolated buildings in time and frequency dual domains, The Structural Design of Tall and Special Buildings, 18(6), 589-606.

Takewaki, I., Fujita, K. and Yoshitomi, S. (2013). Uncertainties in long-period ground motion and its impact on building structural design: Case study of the 2011 Tohoku (Japan) earthquake, Engineering Structures, 49, 119-134.

Takewaki, I., Fujita, K., Yamamoto, K. and Takabatake, H. (2011). Smart passive damper control for greater building earthquake resilience in sustainable cities, Sustainable Cities and Society, 1(1), 3-15.

Takewaki, I. and Fujimoto, H. (2004). Earthquake input energy to soil-structure interaction systems: A frequency-domain approach, Advances in Structural Engineering, 7(5), 399-414.

Takewaki, I., Moustafa, A. and Fujita, K. (2012). Improving the earthquake resilience of buildings: The worst case approach, Springer (London).

Takewaki, I. and Tsujimoto, H. (2011). Scaling of design earthquake ground motions for tall buildings based on drift and input energy demands, Earthquakes and Structures, 2(2), 171-187. 
Tanabashi, R. (1956). Studies on the nonlinear vibrations of structures subjected to destructive earthquakes. Proc. of the First World Conference on Earthquake Engineering, Berkeley, CA, 6:1-16.

Uang, C.M., and Bertero, V.V. (1990). Evaluation of seismic energy in structures. Earthquake Engrg. Struct. Dyn., 19, 77-90.

Westermo, B.D. (1985). The critical excitation and response of simple dynamic systems. $J$. Sound and Vibration, 100(2), 233-242.

Yamamoto, K., Fujita, K. and Takewaki, I. (2011). Instantaneous earthquake input energy and sensitivity in base-isolated building, The Structural Design of Tall and Special Buildings, 20(6), 631-648.

Zahrah, T.F., and Hall, W.J. (1984). Earthquake energy absorption in SDOF structures. J. Structural Engineering, ASCE, 110(8) 1757-1772.

Zhai, C., Chang, Z., Li, S. and Xie, L. (2013). Selection of the most unfavorable real ground motions for low- and mid-rise RC frame structures, $J$ Earthquake Engineering, 17(8), 1233-1251. 